Article

\title{
Surface Decarburization of the Hypo-Eutectoid Carbon Steel C45 during Annealing in Steady Air at Temperatures $T>A_{\mathrm{C} 1}$
}

\author{
Matija Zorc ${ }^{1}$, Aleš Nagode ${ }^{1}$, Jaka Burja ${ }^{2}$, Borut Kosec ${ }^{1}$ and Borut Zorc ${ }^{1,3, *}$ \\ 1 Faculty of Natural Sciences and Engineering, University of Ljubljana, Aškerčeva 12, \\ SI-1000 Ljubljana, Slovenia; matija.zorc@gmail.com (M.Z.); \\ ales.nagode@omm.ntf.uni-lj.si (A.N.); borut.kosec@omm.ntf.uni-lj.si (B.K.) \\ 2 Institute of Metals and Technology, Lepi Pot 11, SI-1000 Ljubljana, Slovenia; jaka.burja@imt.si \\ 3 Welding Institute Ltd., Ptujska 19, SI-1000 Ljubljana, Slovenia \\ * Correspondence: borut.zorc@i-var.si
}

Received: 11 May 2018; Accepted: 1 June 2018; Published: 5 June 2018

\begin{abstract}
The non-alloyed hypo-eutectoid steel C45 was annealed in a steady air atmosphere at $T>A_{\mathrm{C} 1}$ using three temperature ranges and annealing times $t_{a}=\frac{1}{2}, 1$ and $2 \mathrm{~h}$. The oxidation and decarburization obeyed the parabolic law of growth with time and increased with higher temperatures and longer annealing times. The maximum visible thickness of the decarburized surface layer for all the temperature ranges can be predicted from the equations for the oxidation of iron and from the Van-Ostrand-Dewey equation (derived from Fick's 2nd law) for the distribution of carbon. In this relation, the equation that gives the lowest values for the diffusion coefficient of carbon in austenite is appropriate. It was found that the Van-Ostrand-Dewey equation is applicable at $T>A_{\mathrm{C} 1}$, despite the fact that it was derived for the decarburization of austenite at $T>A_{\mathrm{G}}$. A comparison of the results showed that the depth of the decarburization with a carbon content of $0.91-0.98 C_{0}$ can be determined with optical metallography and that both the theoretical and measured values are, in general, mutually accurate in the regions of $93 \%$ to $98 \%$. In practice, visible decarburization might not be present under some conditions while annealing in a steady air atmosphere. The reason for this is that the process of oxidation is faster than the process of decarburization. Considering the oxidation of steel under these conditions, annealing in a steady air atmosphere can be performed without any protective measures.
\end{abstract}

Keywords: carbon steel; annealing; air; oxidation; decarburization

\section{Introduction}

The hot working and annealing associated with most of the heat treatments for non-alloyed and low-alloyed steels takes place in the austenite or austenite-ferrite microstructural region, which means that the annealing temperatures are higher than $A_{C 1}$ [1,2]. Both strong oxidation and decarburization of the steel's surface occur when annealing at these temperatures in an oxidizing atmosphere [3-9]. The decarburization occurs as the steel shifts towards the thermodynamic equilibrium between itself and the atmosphere, but in an oxidizing atmosphere this equilibrium cannot be achieved. Under these conditions the iron oxidizes, mainly into $\mathrm{FeO}$, while the carbon oxidizes into the gaseous products $\mathrm{CO}$ and $\mathrm{CO}_{2}$. The oxidation of the carbon on the steel's surface creates and maintains the concentration gradient of the carbon between the surface and the interior of the steel. A consequence of this is the constant diffusion of the carbon from the interior towards the surface of the steel and the growth of the decarburized surface layer towards the interior. In practice it is necessary to prevent or reduce the decarburization of steel as much as possible, either by using a protective atmosphere or by annealing under conditions for which the process of oxidation is faster than the process of decarburization. 
The reason for these protective measures is a decrease of the resistance to crack initiation in the surface ferrite layer and an increase in the origin of fatigue fracture in the decarburized ferritic surface layer [10].

This article discusses the oxidation and decarburization of a non-alloyed hypo-eutectoid C45 (designated by EN 10027-1 standard) steel surface, both from the theoretical and practical points of view, during annealing in a steady air atmosphere in three temperature ranges above the $A_{\mathrm{C} 1}$ temperature. The temperature ranges are, in accordance with the $\mathrm{Fe}_{-} \mathrm{Fe}_{3} \mathrm{C}$ phase diagram, chosen by considering the microstructure of the steel and the decarburization-induced and controlled microstructural change of the surface layer at the annealing temperatures.

\section{Theoretical Basics}

\subsection{Metallurgical Theory of the Decarburization of Hypo-Eutectoid Carbon Steel at $T>A_{C 1}$}

The decarburization of steel during annealing is an isothermal process that causes a decrease in the content of carbon in the surface layer. Meanwhile, during the isothermal annealing at $T<T_{G}$ $\left(912{ }^{\circ} \mathrm{C}\right)$ there is also a change in the microstructure of the steel's surface. From a microstructural point of view and with respect to the annealing temperature $T_{a}$, the decarburization of the surface at $T>A_{\mathrm{C} 1}$ can be divided into three temperature ranges (Figure 1a): $A_{\mathrm{C} 1}<T_{a}<A_{\mathrm{C} 3}$ (arrow 1), $A_{\mathrm{C} 3}<T_{a}<T_{G}$ (arrow 2) and $T_{a}>T_{G}($ arrow 3$)$.
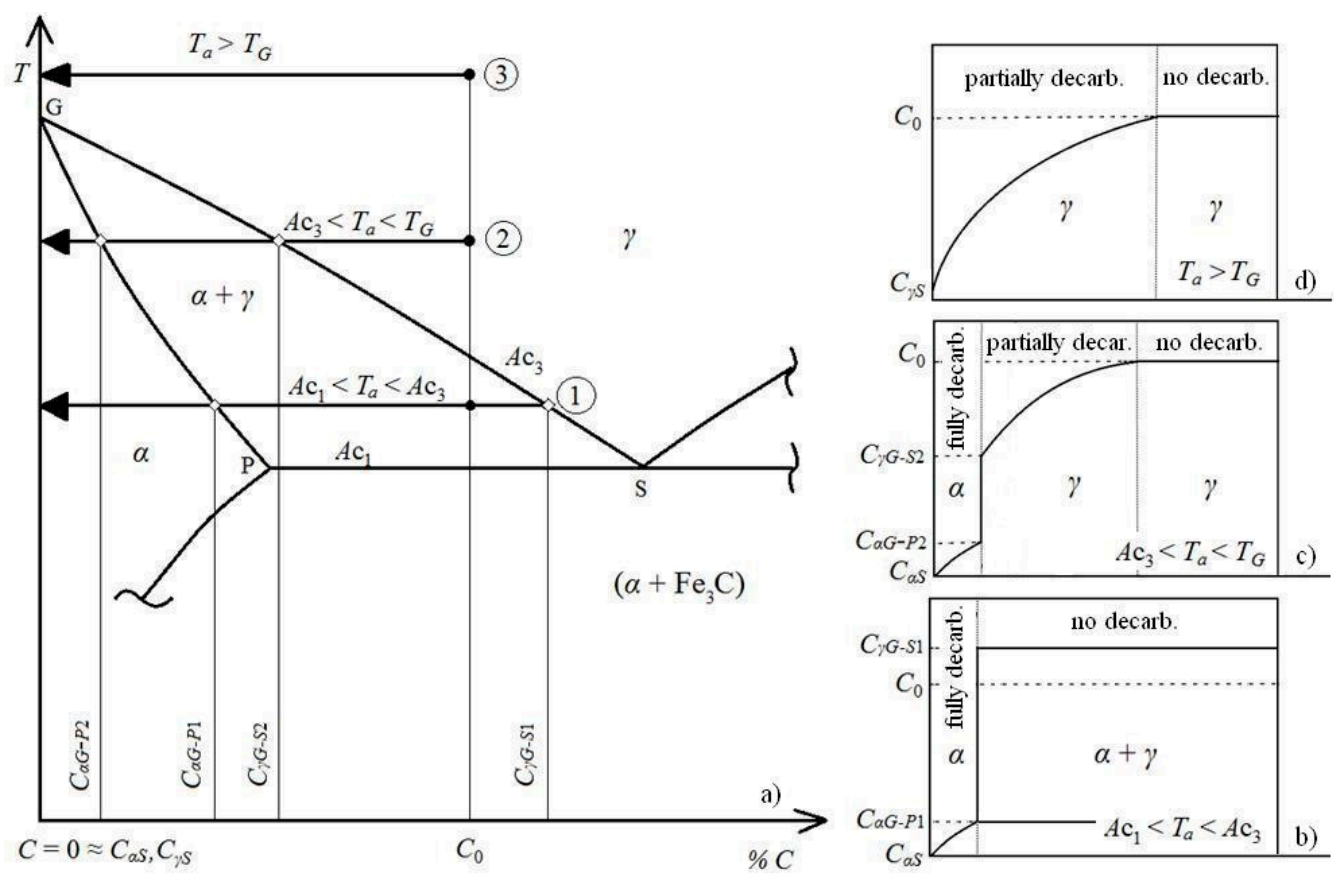

Figure 1. Surface decarburization of non-alloyed hypo-eutectoid steel during isothermal annealing at $T>A_{\mathrm{C} 1}$; (a) Change in the microstructure; $(\mathbf{b}-\mathbf{d})$ concentration profiles of the carbon during the isothermal annealing for the different temperature ranges.

Steel has a ferrite-austenite microstructure during the whole of the annealing time when annealing at the temperatures $A_{\mathrm{C} 1}<T_{a}<A_{\mathrm{C} 3}$ (Figure 1a). At these temperatures a thermodynamic equilibrium exists between the ferrite with a constant carbon content $C \alpha_{G-P 1}$ and the austenite with a constant carbon content $C \gamma_{G-S 1}>C_{0}$. This thermodynamic equilibrium exists for the whole volume of the steel and the consequence is a sharp concentration gradient between both phases (Figure 1a,b). The carbon content of austenite is therefore, during the whole of the annealing time, higher than the initial carbon content of the steel $C_{0}$ (different papers describe the decarburization of the surface in this temperature 
range with an initial carbon concentration $C_{0}$, which is wrong; the decarburization cannot be correctly described because $C_{0}$ is not present in any of the microstructural components at these temperatures; and the initial carbon concentration can only be used at temperatures $T \geq A_{\mathrm{C} 3}$ ). A surface ferritic layer $\alpha_{S}$ will form during the annealing in an oxidizing atmosphere, mostly because of the surface decarburization of the austenite. The carbon content $C \alpha_{S}=0$ is therefore quickly achieved on the outer side of this layer (the phase boundary air $/ \alpha_{S}$ ). Meanwhile, the carbon content on the inner side of this ferrite layer is, all the time, equal to $C \alpha_{S}=C \alpha_{G-P 1}$, which is in equilibrium with the austenite that has a carbon content $C \gamma_{G-S 1}>C_{0}$ during the whole of the annealing time. The state on the inner side of the decarburized ferrite layer $\alpha_{S}$ is therefore the same as the state between the austenite and the ferrite grains in the whole non-decarburized volume of the steel. The equilibrium between the ferrite grains and the carbon-rich austenite in the whole volume of the steel means that the decarburization of the austenite, when annealing in the $(\alpha+\gamma)$ region, is only possible on the inner side of the surface ferrite layer $\alpha_{S}$. The austenite can therefore only decrease its carbon content on the $\alpha_{S} / \gamma$ phase boundary. This means that after cooling there exists only a completely ferritic surface layer, under which there is no visible partially decarburized layer that would have a higher ferrite content compared to the initial microstructure. A more or less frontal growth of the ferrite surface layer $\alpha_{S}$ during the annealing at temperatures $A_{\mathrm{C} 1}<T_{a}<A_{\mathrm{C} 3}$, without a partially decarburized layer, is therefore a consequence of the volume thermodynamic equilibrium between the ferrite with a carbon content $C \alpha_{S}=C \alpha_{G-P 1}$ (the ferrite on the inner side of the ferrite surface layer and all the ferrite grains in the whole volume of the steel) and the austenite with a carbon content $C \gamma_{G-S 1}>C_{0}$ (all the austenite grains in the whole volume of the steel), which consequently causes decarburization of the austenite only, on the inner boundary with the surface ferrite layer $\alpha_{S}$.

Steel has a mono-phase austenite microstructure at $A_{\mathrm{C} 3}<T_{a}<T_{G}$ temperatures (Figure 1a). During the annealing in an oxidizing atmosphere only the decarburization of austenite will occur on the surface at first, while later, when crossing the G-S line, the ferrite surface layer $\alpha_{S}$ will start to form. The carbon content of the ferrite on the outer side of this layer (the phase boundary air $/ \alpha_{S}$ ) quickly reaches the value $C \alpha_{S}=0$, while the carbon content in the ferrite on the inner side of this layer is always $C \alpha_{S}=C \alpha_{G-P 2}$, which is in a thermodynamic equilibrium with the partially decarburized austenite with a carbon content $C \gamma_{G-S 2}<C_{0}$ (Figure 1a,c). The concentration gradient of the carbon between the ferrite on the inner side of the surface layer and the austenite is sharp, while in the austenite it slowly drops with the depth in the direction from $C_{\gamma_{G}-S 2}$ towards $C_{0}$ (Figure 1c), because of the concentration profile of the carbon, defined by the Van-Ostrand-Dewey equation. During annealing in this temperature range there is a decarburized layer that is made of a surface ferrite layer, under which there is a layer of partially decarburized austenite. This is one reason for the existence of a visible, partially decarburized, ferrite-pearlite layer under the completely decarburized ferrite surface layer $\alpha_{S}$ after cooling. This partially decarburized ferrite-pearlite layer shows an increasing content of pearlite as we move towards the interior, until it reaches its equilibrium content at the depth where the carbon content is $C_{0}$. It is known that the thickness of a partially decarburized layer does not change very much during annealing, regardless of the annealing time [9]. The thickness of the partially decarburized layer in this temperature range is therefore controlled by the ratio of the diffusion rates of the carbon in the surface ferrite layer and in the austenite.

When annealing at $T_{a}>T_{G}$ the steel has a mono-phase austenite microstructure for the whole duration of the annealing (Figure 1a), and when annealing in an oxidizing atmosphere the decarburization of the austenite occurs. The carbon concentration in the austenite changes from $C \gamma_{S}=0$ on the surface towards $C_{0}$ in the interior (Figure 1a,d) in accordance with the Van-Ostrand-Dewey equation (derived from Fick's 2nd law), which means that the carbon concentration gradient slowly decreases with the depth. In the case of a complete decarburization of the surface, the microstructure after cooling consists of a ferrite layer, under which is a thick, partially decarburized, ferrite-pearlite microstructure. The pearlite content increases continuously, until it reaches the equilibrium content in the depth with a nominal carbon content $C_{0}$. 
In practice, it is not necessary that all the mentioned microstructures will be visible after cooling. The reason is the velocity of the simultaneous reactions of oxidation and decarburization of the surface at the annealing temperature [5-11]. If the oxidation lags behind the complete decarburization then there is a reduced, completely decarburized layer as well as a whole, partially decarburized layer visible after cooling. If the oxidation and complete decarburization happen with the same rate, it means that after cooling there will only be a whole, partially decarburized layer that is visible. If the rate of oxidation is higher than the rate of complete decarburization and partially higher than the rate of partial decarburization, then there is only a reduced, partially decarburized layer that is visible after cooling. If the process of oxidation is as fast as, or faster than, both the complete and partial decarburization, then there will be no decarburized layer visible after the cooling. The oxidation of steel is faster when the annealing conditions and certain phenomena during annealing greatly reduce or prevent the oxidation of the carbon on the surface. This then prevents the formation of a concentration gradient between the surface and the interior of the steel, which is the basis for the carbon diffusion to the surface (the decarburization conditions and phenomena are discussed in individual sections). The lack of visible decarburization also happens when the annealing time is too short, due to the incubation period, which is a result of the initial surface oxidation and the formation of an impermeable oxide layer.

\subsection{Theoretical Overview of the Oxidation of Hypo-Eutectoid Carbon Steel at $T>A_{\mathrm{C} 1}$}

Steel is non-alloyed when the content of alloying elements does not fundamentally affect the steel's properties. It is a fact that all chemical elements whose affinity for oxygen is higher than that of iron will reduce the rate of oxidation because of the formation of more complex oxide layers, for example, $\mathrm{MnO} \cdot \mathrm{SiO}_{2}$ or $2 \mathrm{MnO} \cdot \mathrm{SiO}_{2}$ [2]. The amounts of these chemical elements in non-alloyed steels are low enough so that their oxide layers are discontinuous and permeable, which means that they can be neglected in a theoretical discussion of the oxidation and decarburization of a non-alloyed steel surface. Accordingly, the only oxidation reactions discussed in the following text are those of iron and carbon (Figure 2a), chosen from the Richardson-Jeffes diagram of oxide formation $\Delta G^{\circ}-T$ [12]. The consequence of the oxidation of iron is an oxide surface layer, while the consequence of the oxidation of carbon is the decarburization of the steel's surface layer. It is important to know that the conditions causing the oxidation of steel also always cause its decarburization.

\subsubsection{Oxidation of Iron}

Air is composed of $78 \mathrm{vol} \% \mathrm{~N}_{2}, 21 \mathrm{vol} \% \mathrm{O}_{2}$ and $1 \mathrm{vol} \%$ other gases. The partial pressure of oxygen in air is therefore $p_{\mathrm{O} 2}=2.1 \times 10^{4} \mathrm{~Pa}=0.21 \mathrm{~atm}$. From the Richardson-Jeffes diagram of the formation of oxides $\Delta G^{\circ}-T$ [12], we can see that iron oxidizes up to its melting point at this pressure. Considering the Fe-O phase diagram, the oxide layer on the iron and non-alloyed steel surface consists of $\mathrm{FeO}$ when annealing in air at temperatures $T>570{ }^{\circ} \mathrm{C}$. In reality the high partial pressure of oxygen and the different valence numbers of iron create an oxide layer consisting of three different oxides at these temperatures. These oxides are present in a sequence from the one with the lowest amount of oxygen closest to the metal to the one with the highest amount of oxygen closest to the atmosphere: $\mathrm{FeO} / \mathrm{Fe}_{3} \mathrm{O}_{4} / \mathrm{Fe}_{2} \mathrm{O}_{3}$-wüstite/magnetite/hematite (Figure $2 \mathrm{~b}$ ). Their relative thickness is mainly constant and not dependent on the thickness of the oxide layer, and at $T>700{ }^{\circ} \mathrm{C}$ is roughly $95 \% \mathrm{FeO}, 4 \% \mathrm{Fe}_{3} \mathrm{O}_{4}$ and $1 \% \mathrm{Fe}_{2} \mathrm{O}_{3}$ [2,11-14]. At the temperature $T=570-800{ }^{\circ} \mathrm{C}$ it is, however, possible to find results that deviate in terms of compositions as well as thicknesses of the individual layers, which demonstrates the complexity of the oxidation of iron and non-alloyed steel in this temperature range [14]. The formation of the three-layered oxide layer can be explained in a simple way using the chemical reactions of the direct oxidation of iron with oxygen. In reality, the formation of the three-layered oxide layer is more complex, as it grows on the phase boundaries $\mathrm{FeO} / \mathrm{Fe}_{3} \mathrm{O}_{4}$ and $\mathrm{Fe}_{3} \mathrm{O}_{4} / \mathrm{Fe}_{2} \mathrm{O}_{3}$, which is a consequence of specific transport processes through the individual oxide 
layers (the outwards diffusion of iron cations and electrons, and the inwards diffusion of oxygen anions; Figure 2b) $[2,15,16]$.

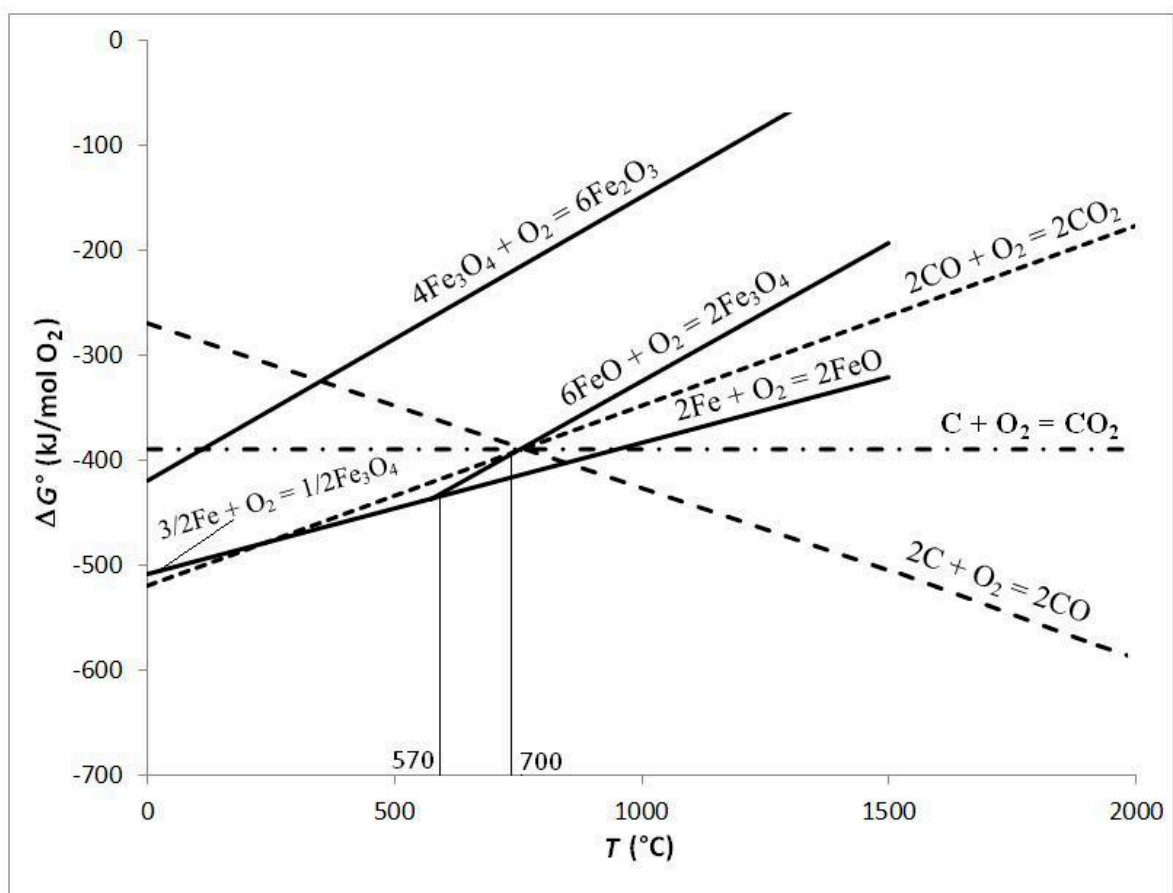

(a)

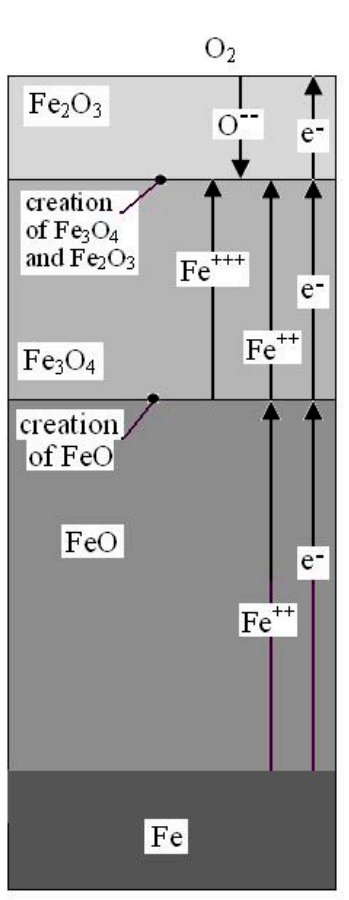

(b)

Figure 2. Oxidation of non-alloyed steel. (a) Richardson-Jeffes diagram of oxidation reactions during the annealing of a non-alloyed steel in air, arranged according to [6,12]; (b) the mechanism of formation of the surface three-layered oxide, arranged according to $[15,16]$.

The composition of the three-layered oxide layer with a majority of $\mathrm{FeO}$ shows that the oxidation of iron and non-alloyed steel at $T>570{ }^{\circ} \mathrm{C}$ is controlled by the formation of $\mathrm{FeO}$. Because oxygen is unable to reach both the metal surface and the phase boundary $\mathrm{FeO} / \mathrm{Fe}_{3} \mathrm{O}_{4}\left(\mathrm{O}^{2-}\right.$ ions travel only from the phase boundary air $/ \mathrm{Fe}_{2} \mathrm{O}_{3}$ through $\mathrm{Fe}_{2} \mathrm{O}_{3}$ onto the phase boundary $\mathrm{Fe}_{2} \mathrm{O}_{3} / \mathrm{Fe}_{3} \mathrm{O}_{4}$ ), $\mathrm{FeO}$ can only grow on the phase boundary $\mathrm{FeO} / \mathrm{Fe}_{3} \mathrm{O}_{4}$ as a consequence of the diffusion of the $\mathrm{Fe}^{2+}$ iron cations through the $\mathrm{FeO}$ in the direction from the metal surface outwards and onto the $\mathrm{FeO} / \mathrm{Fe}_{3} \mathrm{O}_{4}$ phase boundary. Here, a chemical reaction occurs between the iron and the magnetite, creating wüstite:

$$
\mathrm{Fe}_{3} \mathrm{O}_{4}+\mathrm{Fe} \rightarrow 4 \mathrm{FeO}
$$

A fraction of the $\mathrm{Fe}^{2+}$ ions that arrive at the $\mathrm{FeO} / \mathrm{Fe}_{3} \mathrm{O}_{4}$ phase boundary are not used in the reaction and they travel further, together with the $\mathrm{Fe}^{3+}$ ions, through the $\mathrm{Fe}_{3} \mathrm{O}_{4}$ layer, onto the $\mathrm{Fe}_{3} \mathrm{O}_{4} / \mathrm{Fe}_{2} \mathrm{O}_{3}$ phase boundary. Here, the iron reacts with the hematite, creating magnetite:

$$
4 \mathrm{Fe}_{2} \mathrm{O}_{3}+\mathrm{Fe} \rightarrow 3 \mathrm{Fe}_{3} \mathrm{O}_{4}
$$

Because of the constant inflow of oxygen from the air, the hematite never depletes during the formation of magnetite. The constant diffusion of $\mathrm{O}^{2-}$ ions through the $\mathrm{Fe}_{2} \mathrm{O}_{3}$ onto the phase boundary $\mathrm{Fe}_{3} \mathrm{O}_{4} / \mathrm{Fe}_{2} \mathrm{O}_{3}$ means that there is also a constant formation of hematite taking place there. Hematite is formed when the oxide ions react with the $\mathrm{Fe}^{3+}$ ions or with the magnetite. The chemical reactions for the formation of hematite are:

$$
\begin{gathered}
2 \mathrm{Fe}+3 / 2 \mathrm{O}_{2} \rightarrow \mathrm{Fe}_{2} \mathrm{O}_{3} \\
2 \mathrm{Fe}_{3} \mathrm{O}_{4}+1 / 2 \mathrm{O}_{2} \rightarrow 3 \mathrm{Fe}_{2} \mathrm{O}_{3}
\end{gathered}
$$


The thicknesses of the individual oxides in the oxide layer show that iron diffuses much faster in wüstite than in magnetite, and that the diffusion of iron and oxygen through hematite is very slow.

Regardless of the fact that the rate of oxidation of the non-alloyed steel is supposed to be lower than that of the oxidation of iron [14], the growth of the oxide layer on the surface of the iron and the non-alloyed steel at $T>570{ }^{\circ} \mathrm{C}$ is in accordance with the parabolic law [3,14]. The thickness of the oxide layer formed on the surface of the iron $d_{o x}$ is calculated with the following equation $[2,11]$ :

$$
d_{0 x}=\sqrt{6 \cdot t_{a} \cdot e^{\frac{-20392}{T_{a}}}},(\mathrm{~cm})
$$

where $t_{a}$ is the annealing time (s) and $T_{a}$ is the absolute annealing temperature (K).

The three-layered oxide layer based on $\mathrm{FeO}$ does not have a protective character for two reasons: One is the high permeability of $\mathrm{FeO}$ to the diffusion of $\mathrm{Fe}^{2+}$ cations through the oxide because of the presence of cation vacancies in the $\mathrm{FeO}$ crystal structure, which is a consequence of the nonstoichiometric structure (the accurate chemical formula of wüstite is $\mathrm{Fe}_{1-\mathrm{x}} \mathrm{O}$, which means that there are more $\mathrm{O}^{2-}$ anions than $\mathrm{Fe}^{2+}$ cations in the crystal structure; as there is a lack of cations, the electrical neutrality has to be maintained with the presence of cation vacancies and, for example, $\mathrm{Fe}^{3+}$ ions). The second reason is that the oxide layer is not compact, which is a consequence of the porosity and the fractures in the oxide that give the air easy access to the steel's surface. The porosity itself is a consequence of joining the cation vacancies, while the fractures are caused by the limited plasticity, by the inability of the above-critical thickness of the FeO layer to adjust to the steel surface, and by the internal stresses in the oxide that originate from several causes: From the differences between the thermal expansion of $\mathrm{FeO}$ and steel (the $\gamma \rightarrow \alpha$ transformation during the decarburization at $A_{\mathrm{C} 1}<T_{a}<T_{G}$ causes the coefficient of thermal expansion of the steel surface to also change), the differences in the thermal expansion of the individual oxides in the oxide layer, the changes in the composition of $\mathrm{FeO}$ across its thickness, and from the phase transformations of the oxide layers and the steel (the formation of ferrite causes the surface to expand at $A_{\mathrm{C} 1}<T_{a}<T_{G}$, while at $T_{a}>T_{G}$ it shrinks because of the decarburization of austenite). The consequence of the stresses in the oxide is a local decohesion and blistering of the oxide layer (additionally, because of the irregular composition and thickness of the oxide, stresses in the oxide between the areas with blisters and the areas without them form; also gases collect in the blisters, where the pressure increases, and if the critical pressure is reached, they will burst). The tendency for peeling and cracking increases with the greater thickness of $\mathrm{FeO}$; this occurs at thicknesses that are larger than $d_{o x} \approx 50 \mu \mathrm{m}$ [13]. In general, it is known that the oxidation in blisters is slower than in the areas where the oxide tightly fits to the steel surface $[13,14]$. This is a consequence of the bad contact between the peeled oxide layer and the steel surface, and the interrupted flow of the iron ions that is required for the formation of the oxide layer [14].

The volume of the iron oxides is larger than the volume of the steel from which they are formed. This is known as the Pilling-Bedworth ratio $(P B)$ and is equal to 1.67-1.83 for the FeO/Fe- $\alpha$ system, 2.10 for $\mathrm{Fe}_{3} \mathrm{O}_{4} / \mathrm{Fe}-\alpha$ and 2.14 for $\mathrm{Fe}_{2} \mathrm{O}_{3} / \mathrm{Fe}-\alpha$ [2]. The $P B$ ratio for the three-layered oxide layer is calculated in terms of the relative thicknesses of the individual layers. By taking the middle value of the $P B$ for $\mathrm{FeO} / \mathrm{Fe}-\alpha$, the $P B$ ratio for the three-layered Fe-oxide is $P B=1.75 \times 0.95+2.10 \times 0.04+2.14 \times 0.01 \approx 1.77$. This means that the thickness of the oxidized iron $d_{m}$, from which the oxide layer with a thickness of $d_{0 x}$ is created during the annealing at $T>570{ }^{\circ} \mathrm{C}$ in an air atmosphere, is equal to [11]:

$$
d_{m}=0.565 \cdot \sqrt{6 \cdot t_{a} \cdot e^{\frac{-20392}{T_{a}}}},(\mathrm{~cm})
$$

where the $d_{m}$ dimension is important for several reasons. In engineering, it is necessary to increase the thickness of the machine elements by at least $d_{m}$ before annealing. If the machining happens after the annealing then $d_{m}$ must be included as an addition for the mechanical treatment (turning, grinding), which must also include the possible thickness of the decarburized layer. In the theoretical analysis of the diffusion processes in the surface layer, the dimension $d_{m}$ is included in the calculated value of 
the diffusion distance, if the equation does not include the oxidation of the steel. The value of $d_{m}$ is therefore added to the visible or measured thickness of the decarburized layer when determining the absolute depth of the decarburization of non-alloyed steel. Figure 3 shows the calculated values of the thicknesses of the oxide layer $d_{o x}$ and the thicknesses of the oxidized iron $d_{m}$, from which the oxide layer $d_{o x}$ is formed during the annealing in air for the used experimental conditions of the annealing.

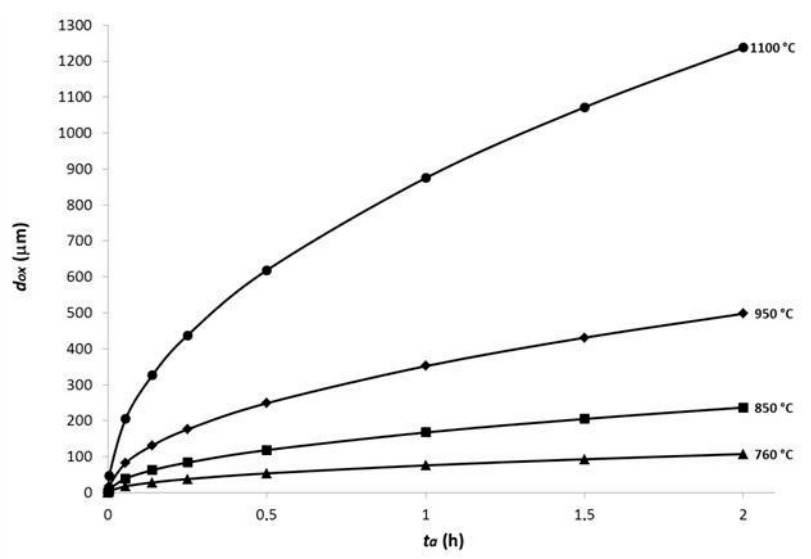

(a)

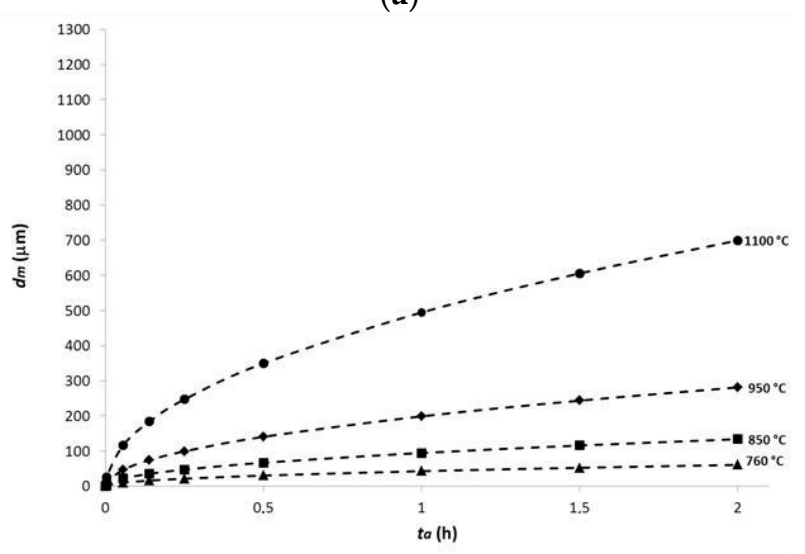

(b)

Figure 3. Oxidation of iron during the annealing in air (our experimental conditions). (a) Calculated thickness of the oxide layer $d_{o x},(\mathbf{b})$ calculated thickness of the oxidized iron $d_{m}$.

\subsubsection{Oxidation of Carbon}

When discussing the oxidation of carbon, it is necessary to take into account the microstructure of the steel at the annealing temperature and the temperature range of the stability for $\mathrm{CO}_{2}$ and $\mathrm{CO}$. Carbon in non-alloyed hypo-eutectoid steel at temperatures $T>A_{\mathrm{C} 1}$ is only present in a solid solution, dissolved in Fe- $\alpha$ (ferrite) and/or in Fe- $\gamma$ (austenite). The ferrite is stable at $T<T_{G}$ or $T<A_{\mathrm{C} 3}$, while the austenite is stable at $T>A_{\mathrm{C} 1}$.

Carbon reacts with oxygen creating $\mathrm{CO}$ and $\mathrm{CO}_{2}$ during the annealing of the steel in air. The reactions of the direct oxidation of carbon with oxygen $\left(\mathrm{C}+\mathrm{O}_{2} \rightarrow \mathrm{CO}_{2}\right.$ and $2 \mathrm{C}+\mathrm{O}_{2} \rightarrow 2 \mathrm{CO}$; Figure 2) intersect at $T \approx 700{ }^{\circ} \mathrm{C}$. The lines of both reactions show that at $T>700{ }^{\circ} \mathrm{C} \mathrm{CO}$ is more stable or that $\mathrm{CO}$ is preferentially formed at $T>A_{\mathrm{C} 1}$. This means that, with respect to the Boudouard equilibrium $\left(\mathrm{C}+\mathrm{CO}_{2} \leftrightarrow 2 \mathrm{CO}\right.$, Figure 2), the reaction goes from left to right at $T>700{ }^{\circ} \mathrm{C}[12,17]$ or that there is a tendency towards decarburization at $T>A_{\mathrm{C} 1}$. Because an increasing temperature means that the carbon preferentially burns to form $\mathrm{CO}$, the equilibrium content of $\mathrm{CO}$ in the formed gas mixture also increases (Figure 4). The equilibrium content of carbon in austenite at the annealing temperature, based on the composition of the atmosphere in the furnace, is shown with lines that are moved to 
the right of the Boudouard equilibrium at $T>A_{\mathrm{C} 1}$ (Figure 4). A curve from which the lines of the equilibrium carbon concentration in austenite are coming out is the equilibrium between the austenite and the ferrite in the two-phase region $(\alpha+\gamma)$, and under this line the equilibrium amount of carbon in ferrite is present. It is important to know that gas mixtures $\left(\mathrm{CO}+\mathrm{CO}_{2}\right)$ cause the decarburization of steel if their composition is below or to the right of the equilibrium line for that steel, while they cause carburization if their composition is above or to the left of that line.

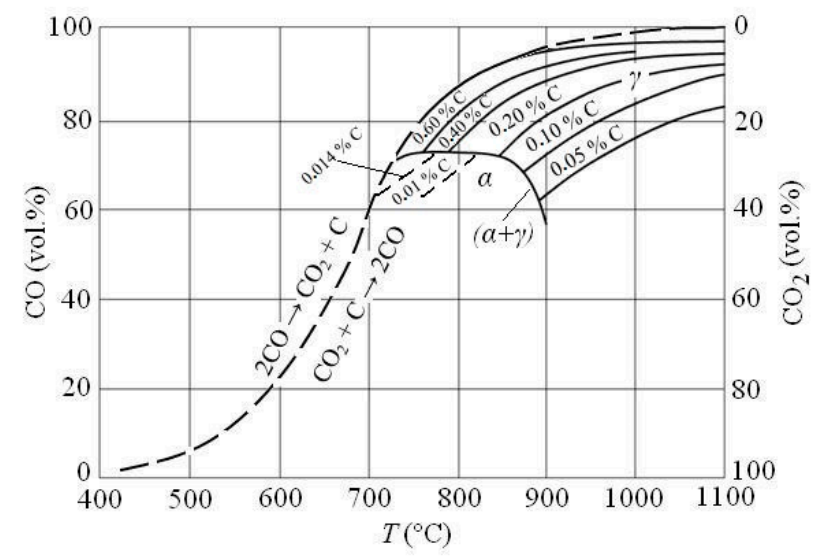

Figure 4. Equilibrium for gas mixtures $\left(\mathrm{CO}+\mathrm{CO}_{2}\right)$ in the $\mathrm{C}-\mathrm{O}$ system for the reactions of decarburization or carburization at pressure $p=1 \mathrm{~atm}$; arranged according to $[15,17]$.

It is important to consider, especially in the initial stage of annealing, that in the initial stage of the steel's oxidation the oxide layer is still compact and the decarburization is suppressed because the formed carbon oxides are unable to enter into the atmosphere. That is to say, the steel/FeO phase boundary is the location of the formation and accumulation of the gas mixture $\left(\mathrm{CO}+\mathrm{CO}_{2}\right)$, the composition of which controls the process of decarburization. There are several oxidation reactions happening simultaneously during the annealing in air at $T>A_{\mathrm{C} 1}$. Because the steel oxidizes already during heating towards the annealing temperature, there is a thin but compact layer of $\mathrm{FeO}$ already present on the steel's surface at $T>A_{\mathrm{C} 1}$. As the oxygen does not diffuse through FeO, the decarburization of the steel's surface in the initial stage of annealing is only possible with the surface reaction of carbon in a solid solution of iron $[C]_{\mathrm{Fe}}$ and wüstite $[3,6,14]$ :

$$
\begin{aligned}
& \mathrm{FeO}+[\mathrm{C}]_{\mathrm{Fe}-\alpha} \rightarrow \mathrm{Fe}-\alpha+\mathrm{CO} \\
& \mathrm{FeO}+[\mathrm{C}]_{\mathrm{Fe}-\gamma} \rightarrow \mathrm{Fe}-\gamma+\mathrm{CO}
\end{aligned}
$$

Initially, the steel decarburizes though both reactions when annealing at $A_{\mathrm{C} 1}<T_{a}<A_{\mathrm{C} 3}$; however, it only decarburizes by Reaction (e) once the continuous ferrite layer is formed. At $A_{\mathrm{C} 3}<T_{a}<T_{G}$ the steel initially decarburizes by Reaction (f), but once a continuous ferrite layer is formed it decarburizes by Reaction (e). Decarburization happens by Reaction (f) at all times at $T>T_{G}$. Part of the formed $C O$ reacts further with $\mathrm{FeO}[3,14]$ :

$$
\mathrm{FeO}+\mathrm{CO} \rightarrow \mathrm{Fe}-\alpha \text { or } \mathrm{Fe}-\gamma+\mathrm{CO}_{2}
$$

Because $\mathrm{CO}$ is more stable at $T>A_{\mathrm{C} 1}$ a part of the formed $\mathrm{CO}_{2}$ reacts further with the carbon dissolved in the solid solution with the Boudouard reaction $[3,6]$ :

$$
\begin{aligned}
& {[\mathrm{C}]_{\mathrm{Fe}-\alpha}+\mathrm{CO}_{2} \rightarrow 2 \mathrm{CO}} \\
& {[\mathrm{C}]_{\mathrm{Fe}-\gamma}+\mathrm{CO}_{2} \rightarrow 2 \mathrm{CO}}
\end{aligned}
$$


The iron formed in Reactions (e)-(g) diffuses through the oxide layer as a result of the constant oxidation; at the same time there is an accumulation of a gas mixture with a high content of $\mathrm{CO}$ at the steel/FeO boundary. Because of this, the decarburization slows down drastically after some time or it can stop for a short period of time. There might even be an occurrence of the carburization of the surface [3]. This means that in the initial phase, after some time, the composition of the created gas mixture $\left(\mathrm{CO}+\mathrm{CO}_{2}\right)$ between the oxide and the steel reaches a composition that lies on the equilibrium lines or even to the left of them (Figure 4). Later, after a short pause, the decarburization accelerates rapidly, which is definitely a consequence of the formation of a highly permeable oxide layer (it can be assumed that, in the case of yet un-cracked blisters of oxide, both the oxidation and decarburization of the steel are reduced on those spots). The formed carbon oxides can go into the atmosphere through the cracks in the oxide layer, while oxygen has free access to the steel surface. From this moment on, it can be considered that the composition of the gas mixture on the steel/FeO boundary is constant and, because of the total surface decarburization, it lies in the ferrite region at $A_{\mathrm{C} 1}<T_{a}<T_{G}$ while lying under the equilibrium line for the austenite with a carbon content of $C=0.05 \mathrm{wt} \%$ at $T_{a}>T_{G}$ (Figure 4). The oxidation of iron increases because of this, while simultaneously also the decarburization increases as the reactions of the direct oxidation of carbon with oxygen start:

$$
\begin{gathered}
2[\mathrm{C}]_{\mathrm{Fe}-\alpha}+\mathrm{O}_{2} \rightarrow 2 \mathrm{CO} \\
{[\mathrm{C}]_{\mathrm{Fe}-\alpha}+\mathrm{O}_{2} \rightarrow \mathrm{CO}_{2}} \\
2[\mathrm{C}]_{\mathrm{Fe}-\gamma}+\mathrm{O}_{2} \rightarrow 2 \mathrm{CO} \\
{[\mathrm{C}]_{\mathrm{Fe}-\gamma}+\mathrm{O}_{2} \rightarrow \mathrm{CO}_{2}}
\end{gathered}
$$

The larger part of the $\mathrm{CO}_{2}$ created by these reactions reacts with the carbon in the solid solution in accordance with Reactions (h) and (i) because of the high temperatures. Decarburization in the ferrite occurs through Reactions (e), (h), (j) and (k), while in the austenite it occurs by Reactions (f), (i), (l) and $(\mathrm{m})$.

After achieving its maximum, the rate of decarburization slowly decreases with an increasing annealing time, showing a decrease in the amount of the formed gases $\mathrm{CO}$ and $\mathrm{CO}_{2}$ [5]. The reason is a continuous surface ferrite layer ( at $A_{\mathrm{C} 1}<T_{a}<T_{G}$ ) or a highly decarburized surface austenite layer (at $T_{a}>T_{G}$ ) with a drastically reduced activity of carbon [4], a small concentration gradient of carbon and also with the diffusion of carbon being a controlled process of decarburization through highly decarburized surface layers. As longer annealing times mean a thicker decarburized surface layer, this also means that the diffusion distance for the carbon atoms in the decarburized layer also increases. This decreases the effectiveness of the driving force for the movement of the carbon atoms through the decarburized layer (the concentration gradient of the carbon slowly decreases with time because of the thickening of the totally decarburized surface layer); the consequence being additional decreases in the process of decarburization. This is why the time dependency of the growth of the decarburized layer, similar to the growth of the oxide layer on the surface of the iron, is parabolic $[3,18]$.

\section{Experimental}

For the purpose of this research, a non-alloyed hypo-eutectoid steel C45 was chosen, the chemical composition of which was measured with an emission spectrometer (in wt \%: $\mathrm{C}=0.43, \mathrm{Si}=0.22$, $\mathrm{Mn}=0.61, \mathrm{P}=0.034, \mathrm{~S}=0.014$ ) with approximate temperatures of phase transitions $A_{\mathrm{C} 1}=735^{\circ} \mathrm{C}$ and $A_{\mathrm{C} 3}=785^{\circ} \mathrm{C}[19]$ and with a ferrite-pearlite initial microstructure. The samples were a rectangular cuboid shape with average dimensions of $40 \mathrm{~mm} \times 30 \mathrm{~mm} \times 17 \mathrm{~mm}$, and with a mass $m=160 \pm 20 \mathrm{~g}$. All the samples were weighed before annealing and placed in groups in such a way that the masses of all three samples annealed at the same temperature for different times were within $5 \mathrm{~g}$ of each other. The surfaces of the samples were grinded and so were without any traces of oxides prior to the annealing. The effect of surface oxides on the kinetics of decarburization was negated with 
grinding prior to annealing, as oxides present on the surface before the annealing increase the visible decarburization [20].

The annealing took place in steady air (the humidity was not measured) at the annealing temperatures $\mathrm{T}_{a}=760^{\circ} \mathrm{C}, 850^{\circ} \mathrm{C}, 950^{\circ} \mathrm{C}, 1100^{\circ} \mathrm{C}$ and the annealing times $t_{a}=\frac{1}{2}, 1,2 \mathrm{~h}$ in a CARBOLITE laboratory electric resistance furnace with the volume of the chamber $\mathrm{V}=22 \mathrm{dm}^{3}$. Each sample was placed in the same spot in the preheated furnace on a firebrick in the middle of the annealing chamber, at the annealing temperature. This ensured the same conditions and the fastest heating of each sample to the annealing temperature. The heating and annealing temperatures were controlled with an ALMEMO 2590-9 certified contact thermocouple that was touching the side of the sample during the annealing (it was inserted into the furnace through the small hole in the ceiling of the furnace). The annealing time was measured from the time when the temperature on the control thermometer reached $T=T_{a}-0.5^{\circ} \mathrm{C}$. The temperature fluctuation during annealing was $T_{a}-1{ }^{\circ} \mathrm{C} \leq T \leq T_{a}+3{ }^{\circ} \mathrm{C}$. The samples were cooled in steady air outside the furnace after the annealing.

The depth of the decarburization was researched using optical microscopy in two ways: Conventionally, with an optical microscope equipped with a reticle, and also with a computer application of the microscope method measuring from a picture on the screen. Metallographic specimens were prepared with wet grinding $\mathrm{SiC}$ paper with a granulation up to \#4000, polishing with a $\frac{1}{4}-\mu \mathrm{m}$ diamond paste and etching with $3 \% \mathrm{HNO}_{3}$ in ethanol. Decarburization of the different surfaces (upper and lateral surfaces that are in contact with the atmosphere, and the bottom surface that is in contact with the firebrick, edges, corners) is not the same because of the different oxidation of these surfaces. Decarburization is, in general, always larger on the surfaces that have less ability to oxidize; therefore, the bottom surfaces are usually decarburized more [4], which also applies to the edges and corners on rectangular cuboid samples $[11,20]$. Both edges and corners are also prone to overheating. This research was focused only on the flat surfaces that were in contact with the atmosphere. The decarburization was measured on three sections perpendicular to the longer side of the sample on the upper and both lateral surfaces of the sample. The depth of the decarburization was also assessed theoretically by taking into account two equations: For the oxidation of the iron and for the distribution of the carbon in the decarburized austenite layer.

\section{Results and Discussion}

\subsection{Oxidation of the Surface of C45 Steel}

The steel's surface oxidizes to a greater extent with higher annealing temperatures and longer annealing times. With a higher temperature (e.g. $\left.T_{a}=1100^{\circ} \mathrm{C}\right)$ there are also more carbon oxides CO and $\mathrm{CO}_{2}$ formed in the same period of time, which means that there is also a high degree of blistering of the oxide layer present after cooling (Figure 5). In the depression in the blistering oxide layer there is a visible fracture that has formed during the isothermal annealing. The proof of this is the very strong decarburization of the steel at this annealing temperature. On the edges the process of oxidation is slower.

The remains of a tightly fitting oxide layer, whose thickness increases with the annealing time, is visible on the samples annealed at $T_{a}=850{ }^{\circ} \mathrm{C}$ as it can be seen in Section 4.2.2. (This is not the total thickness of the oxide layer as its surface layer peeled off during the preparation of the metallographic specimens). The oxide layer is porous, but the steel underneath it is not decarburized, which shows a discontinuous porosity. This proves the assumptions that the degree of clinging of the oxide layer to the steel surface has an important effect on the kinetics of the oxidation and decarburization or, in other words, that the tightly fitting oxide layer prevents decarburization because of the higher oxidation rate of the iron. 


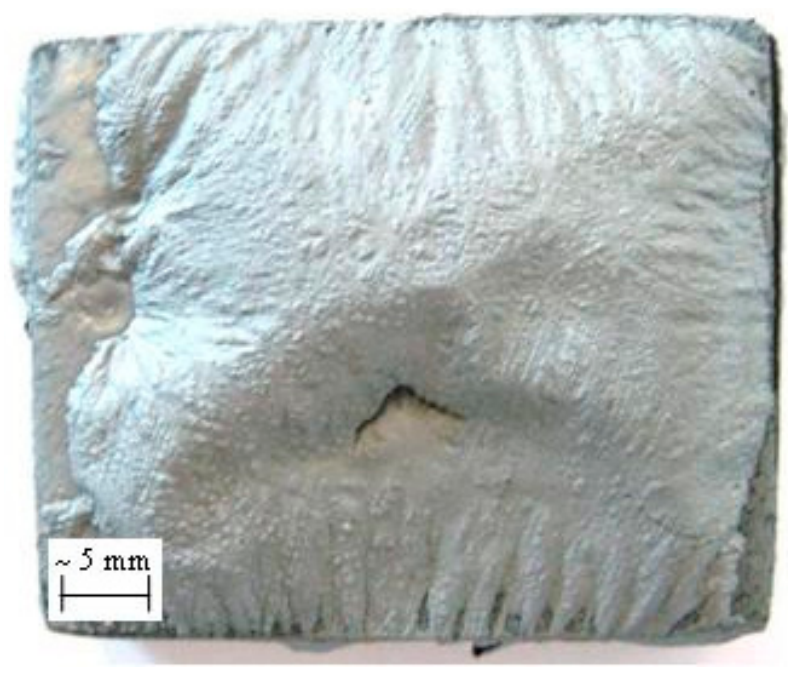

Figure 5. Surface of the sample after one hour of annealing at $T_{a}=1100{ }^{\circ} \mathrm{C}$ and cooling in air.

The thicknesses of the oxide layers on the annealed samples could not be accurately measured as the oxide layers were crumbling and falling off the surface of the samples during their manipulation. Only the pieces of the oxide layer that peeled off from a sample annealed at $T_{a}=1100{ }^{\circ} \mathrm{C}$ for $t_{a}=2 \mathrm{~h}$ could be measured reasonably accurately. Their thickness was larger than $1.0 \mathrm{~mm}$, which is comparable to the calculated results (Figure 3). A comparison of the calculated results with the experimental-analytical results of the oxidation of steel $55 \mathrm{SiCr}$ with $1.51 \mathrm{wt} \% \mathrm{Si}$ and $0.70 \mathrm{wt} \% \mathrm{Cr}$ [8] shows that the $55 \mathrm{SiCr}$ steel oxidizes more slowly than the $\mathrm{C} 45$ steel $\left[(\mathrm{a}) \mathrm{T}_{a}=750{ }^{\circ} \mathrm{C}, t_{a}=1 \mathrm{~h}\right.$, steel 55SiCr: measured $d_{o x}=30 \mu \mathrm{m}$, result calculated with Equation (1): $d_{o x}=69 \mu \mathrm{m}$; (b) $T_{a}=1100{ }^{\circ} \mathrm{C}$, $t_{a}=1 \mathrm{~h}$, steel 55SiCr: measured $d_{o x}=530 \mu \mathrm{m}$, result calculated with Equation (1): $d_{o x}=875 \mu \mathrm{m}$; (c) $T_{a}=1150{ }^{\circ} \mathrm{C}, t_{a}=1 \mathrm{~h}$, steel $55 \mathrm{SiCr}$ : measured $d_{o x}=800 \mu \mathrm{m}$, result calculated with Equation (1): $d_{o x}=1136 \mu \mathrm{m} ;(\mathrm{d}) T_{a}=1200{ }^{\circ} \mathrm{C}, t_{a}=1 \mathrm{~h}$, steel 55SiCr: measured $d_{o x}=1200 \mu \mathrm{m}$, result calculated with Equation (1): $d_{o x}=1449 \mu \mathrm{m}$ ], which is certainly a consequence of the higher content of silicon and the added chromium. Our calculated results are comparable with the measured thicknesses of the oxide layer on carbon steel with the carbon content $\mathrm{C}=0.76 \mathrm{wt} \%$ (defined as base composition in [4]. When also taking into account our measured results for the peeled-off oxide layer after annealing at $T_{a}=1100{ }^{\circ} \mathrm{C}, t_{a}=2 \mathrm{~h}$ we consider that Equation (1) accurately describes the oxidation of non-alloyed C45 steel during annealing in steady air.

\subsection{Decarburization of the Surface of C45 Steel}

\subsubsection{Annealing at Temperature $T=760^{\circ} \mathrm{C}$}

The annealing temperature $T_{a}=760{ }^{\circ} \mathrm{C}$ is in the $A_{\mathrm{C} 1}<T_{a}<A_{\mathrm{C} 3}$ range; therefore, the $\mathrm{C} 45$ steel has a dual-phase microstructure $(\alpha+\gamma)$ during the whole duration of the annealing. This means that in non-alloyed steel with a carbon content $C_{0}=0.43 \mathrm{wt} \%$ both ferrite with the carbon content $C \alpha_{G-P} \approx 0.0175 \mathrm{wt} \%$ and austenite with the carbon content $C \gamma_{G-S} \approx 0.546 \mathrm{wt} \%$ are in equilibrium at this temperature (the values are estimated from the $\mathrm{Fe}^{-} \mathrm{Fe}_{3} \mathrm{C}$ phase diagram, Figure II-4b,II-4c in [1]). During the whole annealing, the concentration gradient of the carbon $\Delta C / \Delta x$ between the ferrite and the austenite is sharp and large $\left(\Delta C_{\alpha / \gamma} \approx 0.529 \mathrm{wt} \% ; x=\right.$ thickness of the crystal boundary, the distance of a few atoms) and constant between all the ferrite and austenite grains in the whole volume of the steel and with the inner side of the decarburized surface layer (Figure 1b). $\Delta C / \Delta x_{\alpha}$ is small in the surface ferrite layer with the surface carbon concentration $C \alpha_{S}=0$ and it additionally decreases with longer annealing times $\left(C \alpha_{S}=0, \Delta C_{\alpha} \approx 0.0175 \mathrm{wt} \%, x_{\alpha}=\right.$ thickness of the ferrite layer, which increases 
with longer annealing times). The microstructure of the surface part of the C45 steel after annealing is shown in Figure 6.
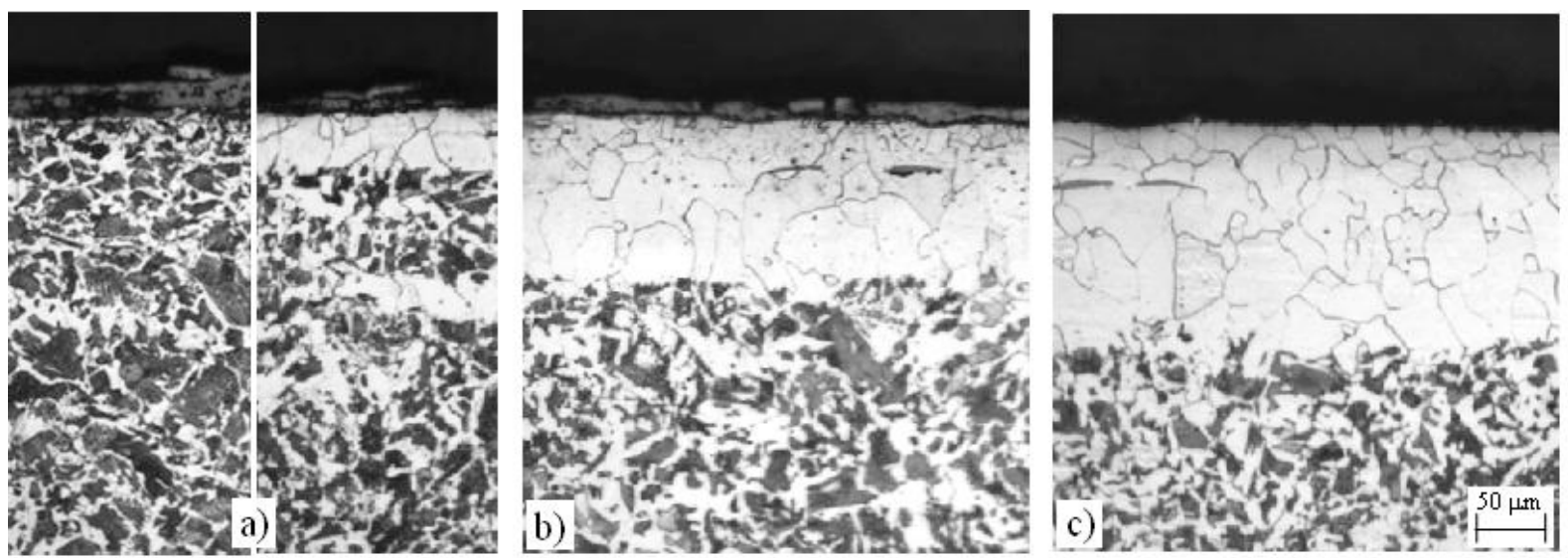

Figure 6. Microstructure of the surface part of $\mathrm{C} 45$ steel after annealing at $T_{a}=760{ }^{\circ} \mathrm{C}$. (a) $t_{a}=\frac{1}{2} \mathrm{~h}$, (b) $t_{a}=1 \mathrm{~h},(\mathbf{c}) t_{a}=2 \mathrm{~h}$.

A clearly visible ferrite layer is formed on the surface as a consequence of the decarburization. Under it there is no visible, partially decarburized layer (see the explanation in Section 2.1). The decarburized layer is discontinuous after short annealing times. There is practically no decarburization on the surface after $t_{a}=\frac{1}{2} \mathrm{~h}$ (Figure 6a-left) and there was only a very locally limited small decarburization area found. The ferrite in this area could have easily been mistaken for a local banded distributed untransformed ferrite in steel, but the ferrite grains in a surface decarburized layer are more polygonal shape (Figure 6a-right). After $t_{a}=1 \mathrm{~h}$ the surface is already strongly decarburized (Figure 6b), part of the decarburized surface is large, while there are still larger areas of surface that did not yet decarburize (here the state is the same as that in Figure 6a-left). After $t_{a}=2 \mathrm{~h}$, there is a continuous decarburized ferrite layer on the surface (Figure $6 \mathrm{c}$ ). The measured maximum thicknesses of the decarburized layers after different annealing times are: $50 \mu \mathrm{m}\left(t_{a}=\frac{1}{2} \mathrm{~h}\right), 120 \mu \mathrm{m}\left(t_{a}=1 \mathrm{~h}\right)$ and $150 \mu \mathrm{m}\left(t_{a}=2 \mathrm{~h}\right)$.

\subsubsection{Annealing at Temperature $T=850^{\circ} \mathrm{C}$}

The annealing temperature $T_{a}=850{ }^{\circ} \mathrm{C}$ is in the $A_{\mathrm{C} 3}<T_{a}<T_{G}$ temperature range; therefore, the $\mathrm{C} 45$ steel has a single-phase $\gamma$ microstructure during the annealing. However, because of the oxidation of carbon from the surface, the surface area of the austenite with the carbon content $C \gamma=C_{0}=0.43 \mathrm{wt} \%$ is depleted in terms of carbon. When the carbon content in the surface area reduces to $C \gamma_{G-S} \approx 0.13 \mathrm{wt} \%$ (from Figure II-4b in [1]), surface ferrite with the carbon content $C \alpha_{G-P} \approx 0.007 \mathrm{wt} \%$ (from Figure II-4c in [1]) starts to form. This ferrite then quickly decarburizes to $C \alpha_{S}=0$ on the surface. The difference in the carbon concentration in the ferrite is very small $\left(\Delta C_{\alpha} \approx 0.007 \mathrm{wt} \%\right)$, while in austenite it is much larger $\left(\Delta C_{\gamma} \approx 0.3 \mathrm{wt} \%\right)$. The carbon concentration gradient $\Delta C / \Delta x$ is, in general, smaller in the ferrite than in the austenite, and it decreases even more with the thickening of the ferrite layer. The carbon concentration gradient between the ferrite and the austenite is constant and sharp, but compared to the annealing at $T_{a}=760{ }^{\circ} \mathrm{C}$, it is much smaller $\left(\Delta C_{\alpha / \gamma} \approx 0.123 \mathrm{wt} \% ; x=\right.$ thickness of the crystal boundary the distance of a few atoms). In the annealed sample, a surface ferrite layer forms because of the decarburization, under which there is a partially decarburized layer up to the depth where the carbon content is the same as the initial content $C_{0}=0.43 \mathrm{wt} \%$ (see the explanation in Section 2.1). The microstructure of the surface part of the C45 steel after the annealing is shown in Figure 7. 

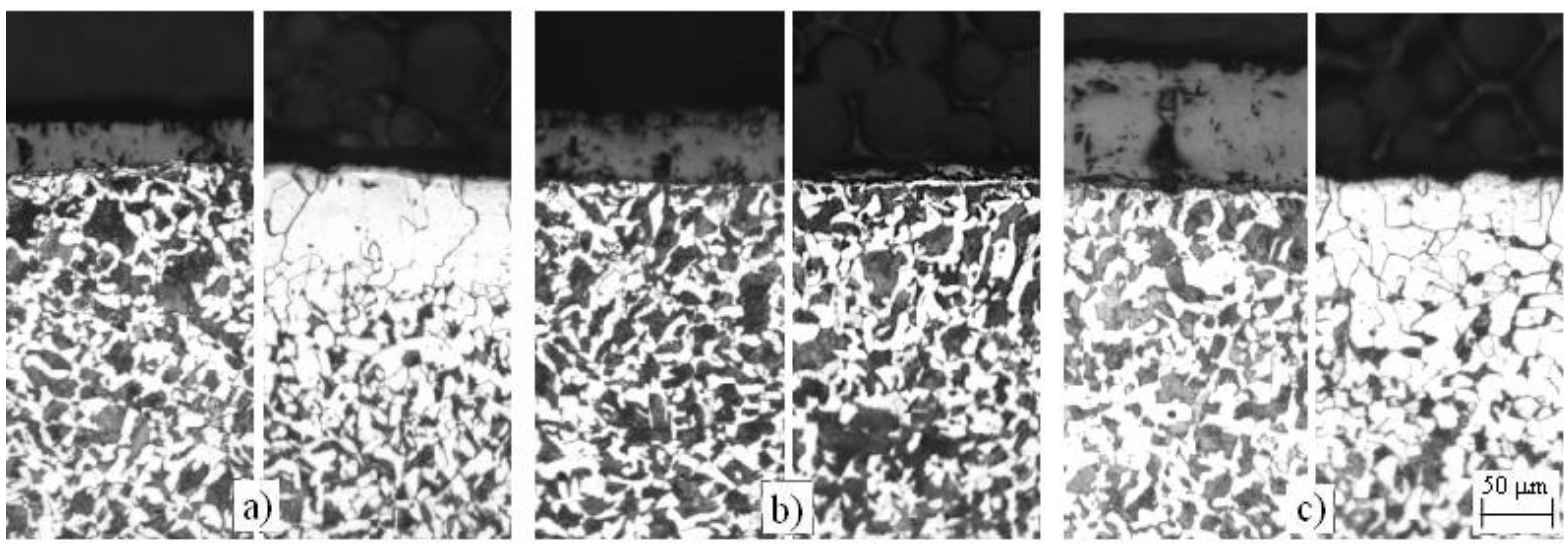

Figure 7. Microstructure of the surface part of C45 steel after annealing at $T_{a}=850{ }^{\circ} \mathrm{C}$. (a) $t_{a}=\frac{1}{2} \mathrm{~h}$, (b) $t_{a}=1 \mathrm{~h},(\mathbf{c}) t_{a}=2 \mathrm{~h}$.

A large part of the surface remains non-decarburized, even after $t_{a}=2 \mathrm{~h}$ (Figure $7 \mathrm{a}-\mathrm{c}$ ), which means that the decarburized surface layer is discontinuous under all annealing conditions. A clearly visible, completely decarburized surface ferrite layer, under which there is a partially decarburized layer, only exists in the samples annealed for $t_{a}=\frac{1}{2} \mathrm{~h}$ and $t_{a}=2 \mathrm{~h}$ (this shows the course of the decarburization, as explained in Section 2.1). After short annealing times the ferrite layer is more pronounced, with coarse ferrite grains, as well as being thicker. The reason for this is the slower oxidation. It is interesting that in samples annealed for $t_{a}=1 \mathrm{~h}$ there is no visible decarburization (actually there exists a very thin, $\leq 3 \mu \mathrm{m}$ thick ferrite layer on some parts of the surface, Figure $7 \mathrm{~b}$-right). The measured maximum thicknesses of the decarburized layers after different annealing times are: Complete decarburization of $160 \mu \mathrm{m}$, including $80 \mu \mathrm{m}$ of ferrite layer $\left(t_{a}=\frac{1}{2} \mathrm{~h}\right.$ ); complete decarburization is equal to the $3 \mu \mathrm{m}$ thick ferrite layer $\left(t_{a}=1 \mathrm{~h}\right)$; and complete decarburization of $280 \mu \mathrm{m}$, including the $70 \mu \mathrm{m}$ of ferrite layer $\left(t_{a}=2 \mathrm{~h}\right)$. The largest anomalies regarding the visible decarburization are found in this temperature range (the characteristic coarse-grained ferrite surface layer is the thickest after $t_{a}=\frac{1}{2} \mathrm{~h}$, the decarburization is practically not visible after $t_{a}=1 \mathrm{~h}$, a large part of the surface is left non-decarburized even after $t_{a}=2 \mathrm{~h}$, and constant thicknesses of the partially decarburized layer are not observed; the results are therefore different to those in, e.g., [9]), but they can be explained by the kinetics of oxidation and decarburization and with different fitting of the oxide, which affects the kinetics of these processes. As mentioned before, in general, there is a tightly fitting oxide layer present on the surface of the samples after cooling, especially on the parts that were not decarburized, showing the effect of fitting of the oxide layer on the decarburization of the steel.

\subsubsection{Annealing at Temperature $T=950^{\circ} \mathrm{C}$}

When annealing at $T_{a}=950{ }^{\circ} \mathrm{C}\left(T_{a}>T_{G}\right)$ in an oxidizing atmosphere the austenite with the carbon content $C \gamma=C_{0}=0.43 \mathrm{wt} \%$ is depleted in terms of carbon in the surface area because of the oxidation of the carbon, which is explained in Section 2.1. The layer of completely decarburized austenite with the carbon content $C \gamma_{S}=0$ forms on the surface, while the carbon content continuously increases towards the interior, until it reaches $C_{0}=0.43 \mathrm{wt} \%$. The strongly decarburized surface austenite is transformed into a surface ferrite layer during the cooling in accordance with the $\mathrm{Fe}^{-} \mathrm{Fe}_{3} \mathrm{C}$ phase diagram. Under this layer there is a partially decarburized layer with an increasing content of pearlite towards the interior (Figure 8). 

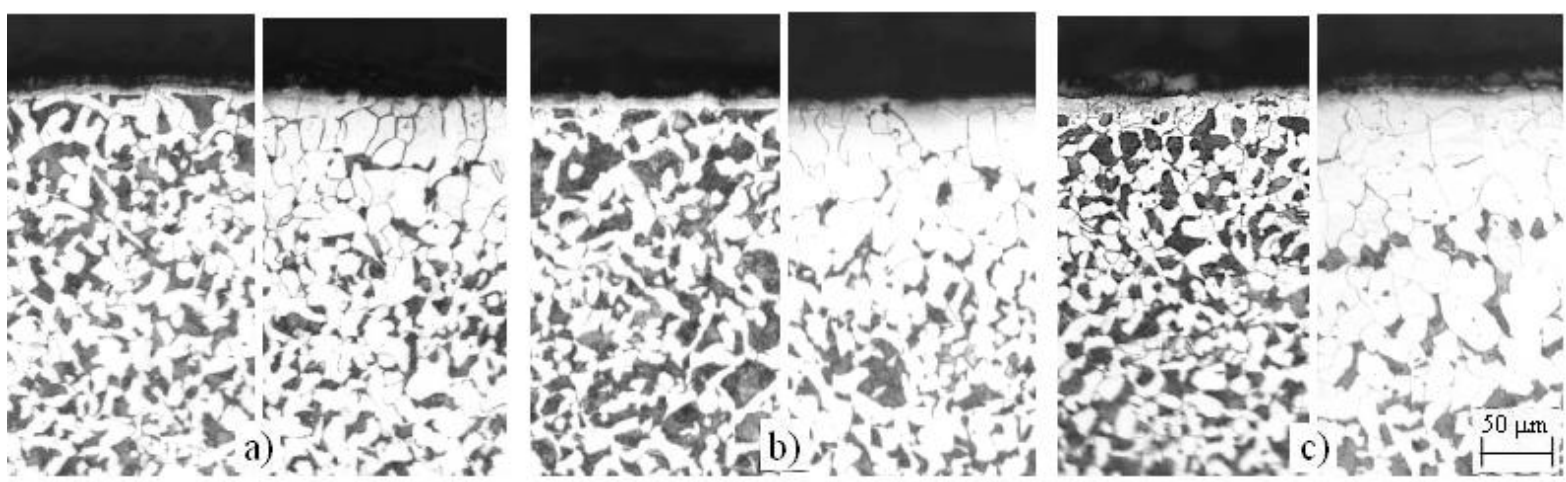

Figure 8. Microstructure of the surface part of C45 steel after annealing at $T_{a}=950{ }^{\circ} \mathrm{C}$. (a) $t_{a}=\frac{1}{2} \mathrm{~h}$, (b) $t_{a}=1 \mathrm{~h},(\mathbf{c}) t_{a}=2 \mathrm{~h}$.

Lower magnifications showed that the surface is discontinuously decarburized even after $t_{a}=2 \mathrm{~h}$. Higher magnifications, meanwhile, showed that there is a very thin continuous ferrite layer in the "non-decarburized surface areas", which becomes thicker with longer annealing times $\left(t_{a}=\frac{1}{2} \mathrm{~h}: \approx 5 \mu \mathrm{m}\right.$, $t_{a}=1 \mathrm{~h}: \approx 10 \mu \mathrm{m}, t_{a}=2 \mathrm{~h}: \approx 15 \mu \mathrm{m}$, left part of Figure $\left.8 \mathrm{a}-\mathrm{c}\right)$. This also applies to the more strongly decarburized areas (right-hand part of Figure $8 \mathrm{a}-\mathrm{c}$ ). The measured maximum thicknesses of the locally decarburized layers are: $200 \mu \mathrm{m}$, including a 40- $\mu \mathrm{m}$-thick ferrite or $75-\mu \mathrm{m}$-thick predominantly ferrite layer $\left(t_{a}=\frac{1}{2} \mathrm{~h}\right) ; 260 \mu \mathrm{m}$, including a $60-\mu \mathrm{m}$-thick ferrite or $100-\mu \mathrm{m}$-thick predominantly ferrite layer $\left(t_{a}=1 \mathrm{~h}\right)$; and $400 \mu \mathrm{m}$, including a $100-\mu \mathrm{m}$-thick ferrite or $150-\mu \mathrm{m}$-thick predominantly ferrite layer $\left(t_{a}=2 \mathrm{~h}\right)$. The steel is, in general, not overheated under these annealing conditions, which is demonstrated by the small polygonal grains.

\subsubsection{Annealing at Temperature $T=1100{ }^{\circ} \mathrm{C}$}

The austenite with the carbon content $C \gamma=C_{0}=0.43 \mathrm{wt} \%$ is depleted in terms of carbon in the surface area because of the oxidation of carbon from the surface when annealing at $T_{a}=1100{ }^{\circ} \mathrm{C}$ $\left(T_{a}>T_{G}\right)$ in an oxidizing atmosphere. There are similar concentration gradients of carbon and the same phenomena exist in steel as when annealing at $T_{a}=950^{\circ} \mathrm{C}$, but the kinetics are faster because of the higher temperature.

The whole surface is decarburized and the decarburized layer is clearly visible (Figure 9). On the surface there is a predominantly ferrite layer. Under this predominantly ferrite layer, the ferrite content continuously decreases with depth, while a higher content of intergranular ferrite shows a more intense diffusion of carbon along the austenite grain boundaries. The steel is strongly overheated, which is shown by the coarse pearlite grains and by the coarse Widmanstätten ferrite microstructure of the partially decarburized layer. The measured maximum thicknesses of the decarburized layers are: $650 \mu \mathrm{m}$, including a 200- $\mu \mathrm{m}$-thick predominantly ferrite layer $\left(t_{a}=\frac{1}{2} \mathrm{~h}\right) ; 1000 \mu \mathrm{m}$, including a $260-\mu \mathrm{m}$-thick predominantly ferrite layer $\left(t_{a}=1 \mathrm{~h}\right)$; and $1400 \mu \mathrm{m}$, including a $300-\mu \mathrm{m}$-thick predominantly ferrite layer $\left(t_{a}=2 \mathrm{~h}\right)$. 

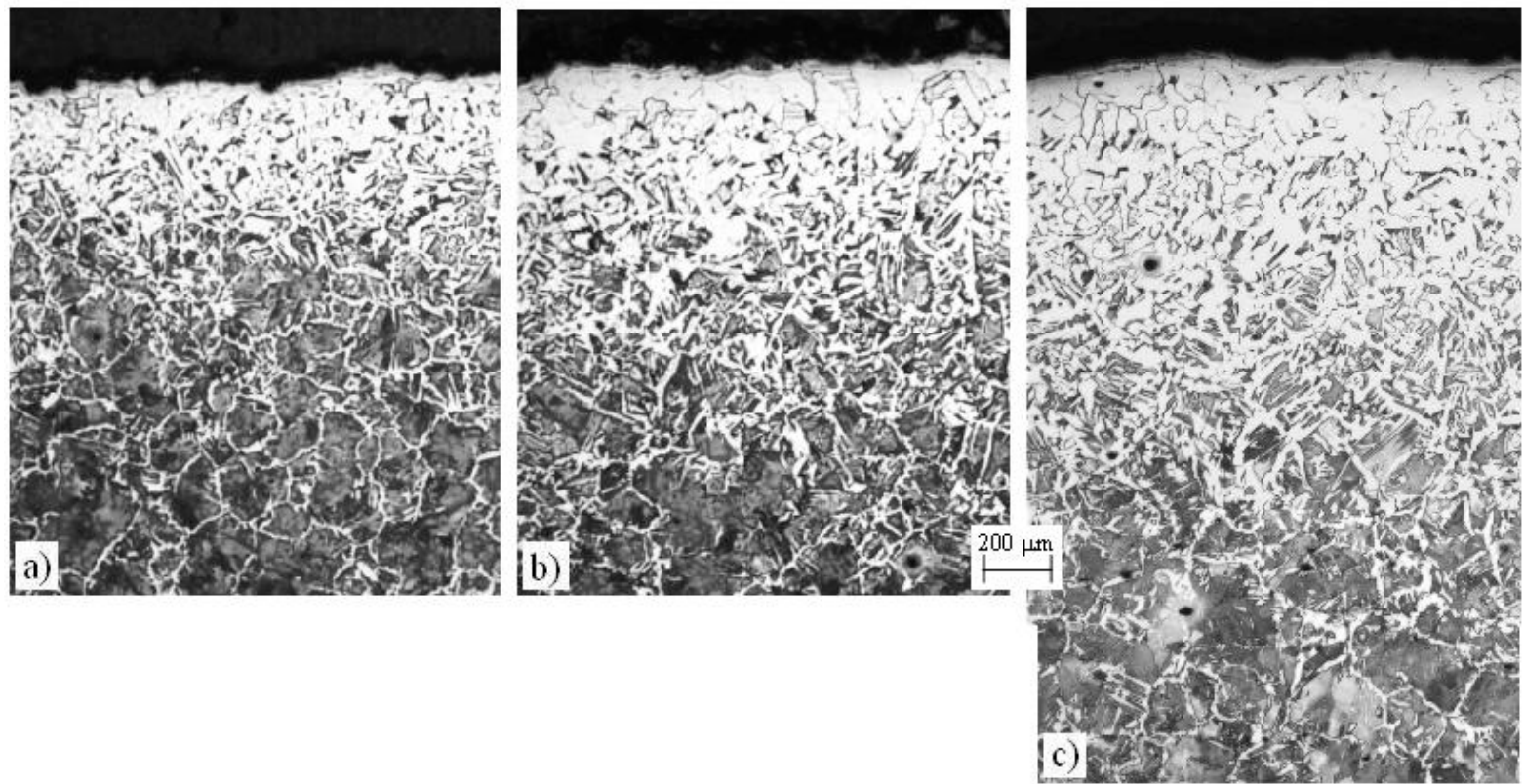

Figure 9. Microstructure of the surface part of C45 steel after annealing at $T_{a}=1100{ }^{\circ} \mathrm{C}$. (a) $t_{a}=\frac{1}{2} \mathrm{~h}$, (b) $t_{a}=1 \mathrm{~h},(\mathrm{c}) t_{a}=2 \mathrm{~h}$.

\subsection{Theoretical Assessment of the Thickness of the Decarburized Layer}

A theoretical discussion of the depth of the decarburization is not simple. During annealing in air the decarburization of steel is initiated by the general oxidation of the steel surface, because of the high partial pressure of oxygen. The reactions of oxidation and decarburization happen at the same time; therefore, the different effects on both processes intertwine, some proportionately and some inversely proportionately. As mentioned earlier, the decarburization is visible only if the oxidation of the steel surface is slower than its decarburization, i.e., when the oxidation of carbon and the carbon diffusion rate is greater than the oxidation rate). Visible decarburization depends on the oxidation potential of the annealing atmosphere, which also determines the degree of oxidation of the surface. This is the reason for the great differences in the visible decarburization that occurs when annealing in air or, e.g., in a mixture of $\mathrm{N}_{2}+2 \% \mathrm{O}_{2}$ [8]. Visible decarburization is always larger when annealing in atmospheres with a low oxygen content $[8,10]$. It is also affected by the fitting of the oxide layer to the steel surface (poor fitting of the oxide layer increases decarburization due to the reduction of the oxidation rate) and its permeability for the gases (non-permeable oxide layer reduces the decarburization), the carbon content in the steel, and the cooling rate after annealing, while different alloying elements affect the kinetics of oxidation and decarburization. With low cooling rates, when the steel is cooled in the furnace, decarburization also happens during the cooling, especially in the two-phase $(\alpha+\gamma)$ region where the surface ferrite layer thickens due to slower oxidation. Therefore, in reference to the isothermal annealing, the visible decarburization increases. Conversely, in hypo-eutectoid non-alloyed steels the whole visible decarburization decreases with faster cooling rates. This is a consequence of lowering and bringing closer together the $A_{\mathrm{r} 3}$ and $A_{\mathrm{r} 1}$ temperatures and with that the conditioned lower content of ferrite at the expense of an increased pearlite content [10,15]. At some point, for each steel characteristic, the critical cooling rate, the $A_{\mathrm{r} 3}$ and $A_{\mathrm{r} 1}$ temperatures become equal. At that point there is no more pro-eutectoid ferrite in the microstructure. If the cooling rate is, therefore, high enough for the partially decarburized layer, then the pro-eutectoid ferrite will no longer form in this layer as well and only pearlite will exist there. At even higher cooling rates there is a formation of bainite or martensite in the partially decarburized layer. The partially decarburized layer is not completely visible at higher cooling rates because of this and it might completely disappear at a high enough cooling rate, with only the completely decarburized surface layer left visible. Metallographically, 
the determined depth of decarburization is therefore always smaller than the actual depth, and the difference becomes larger with higher cooling rates after the annealing. In a metallographic analysis it is also necessary to consider the limited ability of the human eye to detect small differences in the ferrite and pearlite contents or globular cementite in the ferrite (sferoidizing state), which additionally reduces the assessed thickness of the decarburized layer and increases the observational error. More precise values of the depth of the decarburization are determined by microhardness measurements but these are still not as accurate as the actual depths measured using chemical analyses [20,21].

There are various models and equations available for calculating the decarburized layer. All are based on Fick's 2nd law. The uncorrected and corrected Van-Ostrand-Dewey equation $[5,6,8,22,23]$ is used for annealing temperatures $T_{a}>T_{G}$, as well as a Fourier analysis [23]. The Van-Ostrand-Dewey equation is also used and corrected for creating a diffusion model of decarburization that is based on microhardness measurements [21]. For annealing temperatures $T_{a}<T_{G}$ the equations for the calculation of the completely decarburized surface ferrite layers are known $[5,9,22,24]$. Some equations also take into account the oxidation of the surface $[6,9,16,22,24,25]$. The thickness of the decarburized layer can also be calculated from the amount of released gaseous carbon oxides [5]. The equations are corrected in different ways or there are algorithms created in such a way that the calculated values for a selected carbon diffusion coefficient are close to the values obtained by the experiments (the possible reasons for discrepancies between the calculated and measured values are described in the previous paragraph). Any discrepancies are also the consequence of a chosen carbon diffusion coefficient in the austenite, which increases with a higher carbon content in the steel $[1,2,26]$. Because of the different ways of determining the carbon diffusion coefficient in austenite, there are many similar equations that give different values at the same temperature as a consequence of the different pre-exponential factors and activation energies [2,8-10,25-28]. We found that the highest values of the carbon diffusion coefficient in austenite $D_{C \gamma}$ are given by an equation from the literature [27], while the lowest values are given by an equation from the literature [28]:

$$
\begin{aligned}
& \text { literature [27]: } D_{C \gamma}=0.15 \cdot e^{\frac{-135000}{R \cdot T_{a}}},\left(\mathrm{~cm}^{2} / \mathrm{s}\right) \\
& \text { literature [28]: } D_{C \gamma}=0.23 \cdot e^{\frac{-148000}{R \cdot T_{a}}},\left(\mathrm{~cm}^{2} / \mathrm{s}\right)
\end{aligned}
$$

In both equations, $T_{a}$ is the absolute annealing temperature $(\mathrm{K})$ and $R$ is the gas constant $(8.314 \mathrm{~J} / \mathrm{mol} \cdot \mathrm{K})$. The values that were calculated with other equations from other literature sources as well as diffusion coefficient values read from the diagrams in $[1,26]$ lie in this range. The diffusion coefficients $D_{C_{\gamma}}$ calculated from both equations for the used experimental temperatures are presented in Table 1.

Table 1. Carbon diffusion coefficients in austenite $D_{C_{\gamma}}$ calculated using Equations (1) and (2).

\begin{tabular}{cccccc}
\hline Equation & $\boldsymbol{T}_{\boldsymbol{a}}\left({ }^{\circ} \mathrm{C} / \mathrm{K}\right)$ & $\mathbf{7 6 0 / 1 0 3 3}$ & $\mathbf{8 5 0 / 1 1 2 3}$ & $\mathbf{9 5 0 / 1 2 2 3}$ & $\mathbf{1 1 0 0 / 1 3 7 3}$ \\
\hline$(3)$ & $D_{C_{\gamma}}\left(\mathrm{cm}^{2} / \mathrm{s}\right)$ & $2.236 \times 10^{-8}$ & $7.880 \times 10^{-8}$ & $2.570 \times 10^{-7}$ & $1.096 \times 10^{-6}$ \\
$(4)$ & $D_{C_{\gamma}}\left(\mathrm{cm}^{2} / \mathrm{s}\right)$ & $7.546 \times 10^{-9}$ & $3.000 \times 10^{-8}$ & $1.097 \times 10^{-7}$ & $5.382 \times 10^{-7}$ \\
\hline
\end{tabular}

Method of Calculating the Thickness of the Decarburized Layer

We assumed that only the decarburization of austenite takes place under all the annealing conditions (decarburization of the surface ferrite layer was disregarded because of the small concentration gradient, even though the process is controlled by the burning of carbon on the surface of the ferrite layer and by the diffusion of carbon through the ferrite layer). Therefore, we theoretically assessed the thickness of the decarburized layer using the Van-Ostrand-Dewey equation, which describes the decarburization of austenite in terms of the annealing temperature and time [6,29]:

$$
C_{x}=C_{0} \cdot \operatorname{erf}\left[x /\left(2 \cdot \sqrt{D_{C \gamma} \cdot t_{a}}\right)\right]
$$


where: $C_{x}$ is the carbon content in the steel at a distance $x$ from the surface, $C_{x} \leq C_{0}$ (wt \%); $C_{0}$ is the carbon content in the steel (wt \%); $D_{C \gamma}$ is the diffusion coefficient of the carbon in the austenite at $T_{a}$ temperature $\left(\mathrm{cm}^{2} / \mathrm{s}\right) ; t_{a}$ is the annealing time at $T_{a}$ temperature (s); and $\operatorname{erf}[u]$ is the Gauss error function [30].

When calculating the absolute depth of the decarburization, a distance $x=x_{A}$ is assumed, where the carbon content is equal to $C_{x}=C_{x A}=A \times C_{0} . A$ is the factor of decarburization and is equal to $A=C_{x A} / C_{0} \leq 1$ (because of the different assumed distances $x_{A}$ in literature, there are also different values reported for $A$, e.g., 0.85 [8], 0.90 [6], 0.925 [16,25] and 0.98 [23]). In the literature [16,25], it mentions that it is possible to theoretically assess the depth of the decarburization with a $97 \%$ accuracy at the depth $x_{A}=x_{0.925}$ with the carbon content $C_{x A}=A \times C_{0}=0.925 C_{0}$, which is also supposed to be a limit value for the ability to determine the thickness of the decarburized layer by metallography. Equation (5) makes it possible to approach the calculated values with experimental measurements by the method of trial and error, and in this way determine the most appropriate diffusion coefficient of the carbon for a theoretical assessment of the depth of decarburization for concrete experimental conditions. From Equation (5) it follows that $A=\operatorname{erf}\left[x_{A} /\left(2 \cdot \sqrt{D_{C \gamma} \cdot t_{a}}\right)\right]$ and consequently from the table for erf $[u]$, that $x_{A} /\left(2 \cdot \sqrt{D_{C \gamma} \cdot t_{a}}\right)=B$. From this equation the depth $x_{A}$ is calculated, at which there is a carbon content $C_{x A}$ after annealing:

$$
x_{A}=2 \cdot B \cdot 10^{4} \cdot \sqrt{D_{C \gamma} \cdot t_{a}},(\mu \mathrm{m})
$$

where: $D_{C \gamma}$ is the diffusion coefficient of carbon $\left(\mathrm{cm}^{2} / \mathrm{s}\right)$ in austenite at the temperature $T_{a}(\mathrm{~K}) ; t_{a}$ is the annealing time (s) at $T_{a}$, where we can use $10^{4}$ to the convert from $\mathrm{cm}$ to $\mu \mathrm{m}$.

It was shown that the applicable equation in our case of decarburization is Equation (4) with the lowest values of the diffusion coefficient $D_{C \gamma}$. The appropriateness of the lowest $D_{C_{\gamma}}$ for the analysis of decarburization was already reported in $[16,25]$, where the equation for decarburized austenite with the carbon content $C=0$ was used for the calculation of $D_{C \gamma}$, although it gives slightly higher values in comparison to Equation (4). The Equation (4) or $D_{C \gamma}$ values calculated with it are already included in all further derivatives of Equation (6). The calculations showed that the absolute depth of the decarburization for $\mathrm{C} 45$ steel with the carbon content $\mathrm{C}=0.43 \mathrm{wt} \%$ for the used annealing temperatures in steady air is best given using the following derivatives of Equation (6):

$$
\begin{aligned}
T_{a}=760{ }^{\circ} \mathrm{C}: A & =0.966 \text { and } B \approx 1.50 ; x_{A}=x_{0.966}=2.6060 \cdot \sqrt{t_{a}},(\mu \mathrm{m}) \\
T_{a}=850{ }^{\circ} \mathrm{C}: A & =0.962 \text { and } B \approx 1.47 ; x_{A}=x_{0.962}=5.0922 \cdot \sqrt{t_{a}},(\mu \mathrm{m}) \\
T_{a}=950{ }^{\circ} \mathrm{C}: A & =0.910 \text { and } B \approx 1.20 ; x_{A}=x_{0.910}=7.9490 \cdot \sqrt{t_{a}},(\mu \mathrm{m}) \\
T_{a}=1100{ }^{\circ} \mathrm{C}: A & =0.980 \text { and } B \approx 1.65 ; x_{A}=x_{0.980}=24.2095 \cdot \sqrt{t_{a}},(\mu \mathrm{m})
\end{aligned}
$$

As Equations (6)-(10) do not take the oxidation of the steel into consideration, the $x_{A}$ represents the absolute depth of the decarburization $\left(x_{A}=d_{d e c}^{a b s}\right)$, which is equal to the sum of thicknesses of the visible decarburization and the oxidized steel $d_{m}$. The calculated theoretical visible thickness of the decarburization $d_{d e c}^{\text {th }}$ is therefore equal to:

$$
d_{d e c}^{t h}=x_{A}-d_{m}
$$

If surface hardness is the decisive factor for a particular product, then it is appropriate for the steel to be decarburized, reducing the carbon content so that it still gives the lowest value of hardness on the surface based on the Jominy graph. How is a still-acceptable theoretical factor of decarburization $A$ for a particular steel determined? The lowest acceptable theoretical value $A$, and with that a still-acceptable depth of decarburization $x_{A}$ is determined by transferring the lowest value of the hardness of the surface from the Jominy graph to the diagram for martensite hardness vs. carbon content (Figure 13 
in [31]). Then a curve with the appropriate martensite content is chosen by taking into account the content of retained austenite in the microstructure, the carbon content in the steel for the selected hardness is read and, finally, a value for $A$ is calculated. The hardness of the surface in the Jominy graph for C45 steel is 55-62 HRC and the carbon content is $C=0.42-0.50 \mathrm{wt} \%$ [19,32]. As a very low retained austenite content is typical for carbon steels, the curve corresponding to $99 \%$ martensite in the microstructure is chosen. The curve shows that at $99 \%$ martensite in the microstructure, 55 HRC is achieved with a carbon content $\mathrm{C} \approx 0.38 \mathrm{wt} \%=C_{x A}$. Considering the hardness, this carbon content is the lowest acceptable theoretical carbon content for C45 steel. (The correctness of this approach is proven by the Jominy graph for C45 and C35 steels, which partially overlap [32]. The hardness of the surface in the Jominy graph of C35 steel is $48-58 \mathrm{HRC}$ and carbon content is C $=0.32-0.39 \mathrm{wt} \%$ ). Based on this, the lowest acceptable value for the factor of decarburization for $\mathrm{C} 45$ steel with the carbon content $\mathrm{C}=0.43$ wt $\%$ is $A=C_{x A} / C_{0}=0.38 / 0.43=0.884$. The depth $x_{0.884}$ is calculated using Equation (6), adjusted to these circumstances:

$$
\text { for } C_{x A}=0.38 \mathrm{wt} \%: A=0.884 \text { and } B \approx 1.11 ; x_{0.884}=10647 \cdot \sqrt{t_{a} \cdot e^{\frac{-17801}{T_{a}}}},(\mu \mathrm{m})
$$

where: $T_{a}$ is the absolute annealing temperature $(\mathrm{K})$, and $t_{a}$ is the annealing time (s) at the temperature $T_{a}$. By analogy with Equation (11), the theoretical visible depth $d_{d e c}^{t h} 0.884$ at the carbon content $\mathrm{C} \approx 0.38 \mathrm{wt} \%$ from the outer steel surface of the sample towards the interior is:

$$
d_{d e c}^{\text {th }} 0.884=x_{0.884}-d_{m}
$$

The depth of the theoretically still-acceptable decarburization $d_{d e c}^{\text {th } 0.884}$ for C45 steel with $C_{0}=0.43 \mathrm{wt} \%$ is therefore the minimum thickness required to be cut off after annealing in steady air, which should still ensure the lowest acceptable hardness of the surface of C45 steel after the correct quenching. The measured $d_{d e c}^{v i s}, d_{\alpha S}^{v i s}$ and the theoretical decarburization depths $d_{d e c}^{t h}, d_{d e c}^{t h} 0.884$ are presented in Table 2, while the relations of the visible thicknesses of the decarburization related to the annealing time and temperature are graphically shown in Figure 10.

\begin{tabular}{|c|c|c|c|c|c|c|c|c|c|}
\hline$T_{a}\left({ }^{\circ} \mathrm{C}\right)$ & $t_{a}(\mathrm{~s})$ & $d_{m}$ & $x_{A}$ & $d_{d e c}^{\text {th }}$ & $d_{d e c}^{v i s}$ & $d_{\alpha S}^{v i s}$ & $d_{d e c}^{t h} / d_{d e c}^{v i s}$ & $x_{0.884}$ & $d_{d e c}^{\text {th }} 0.884$ \\
\hline \multirow{3}{*}{760} & 1800 & 31 & 110 & 79 & 50 & 50 & 1.580 & $82 ; 118$ * & $51 ; 87$ * \\
\hline & 3600 & 43 & 156 & 113 & 120 & 120 & 0.942 & $116 ; 167$ * & $73 ; 124$ * \\
\hline & 7200 & 61 & 221 & 160 & 150 & 150 & 1.067 & $164 ; 236$ * & $103 ; 175$ \\
\hline \multirow{3}{*}{850} & 1800 & 67 & 216 & 149 & 160 & 80 & 0.931 & 163 & 96 \\
\hline & 3600 & 95 & 305 & 210 & 3 & 3 & 70.00 & 231 & 136 \\
\hline & 7200 & 134 & 432 & 298 & 280 & 70 & 1.064 & 326 & 192 \\
\hline \multirow{3}{*}{950} & 1800 & 141 & 337 & 196 & 200 & $40 ; 75^{\#}$ & 0.980 & 312 & 171 \\
\hline & 3600 & 199 & 477 & 278 & 260 & $60 ; 100$ \# & 1.069 & 441 & 242 \\
\hline & 7200 & 282 & 674 & 392 & 400 & $100 ; 150$ \# & 0.980 & 624 & 342 \\
\hline \multirow{3}{*}{1100} & 1800 & 350 & 1027 & 677 & 650 & $200^{\#}$ & 1.041 & 691 & 341 \\
\hline & 3600 & 477 & 1452 & 975 & 1000 & $260^{\#}$ & 0.975 & 977 & 500 \\
\hline & 7200 & 699 & 2054 & 1355 & 1400 & 300 \# & 0.968 & 1382 & 683 \\
\hline
\end{tabular}

Table 2. Calculated and measured maximum thicknesses of decarburized layer.

Note: all distances are in $(\mu \mathrm{m}) ; d_{d e c}^{\text {th }}$-calculated theoretical visible thickness of decarburization; $d_{d e c}^{v i s}-$ maximum measured visible thickness of decarburization; $d_{\alpha S}^{v i s}$-maximum measured thickness of ferrite or predominantly ferrite layer; " predominantly ferrite layer; ${ }^{*}$ values $x_{0.976}$ and $d_{d e c}^{\text {th }} 0.976$. 


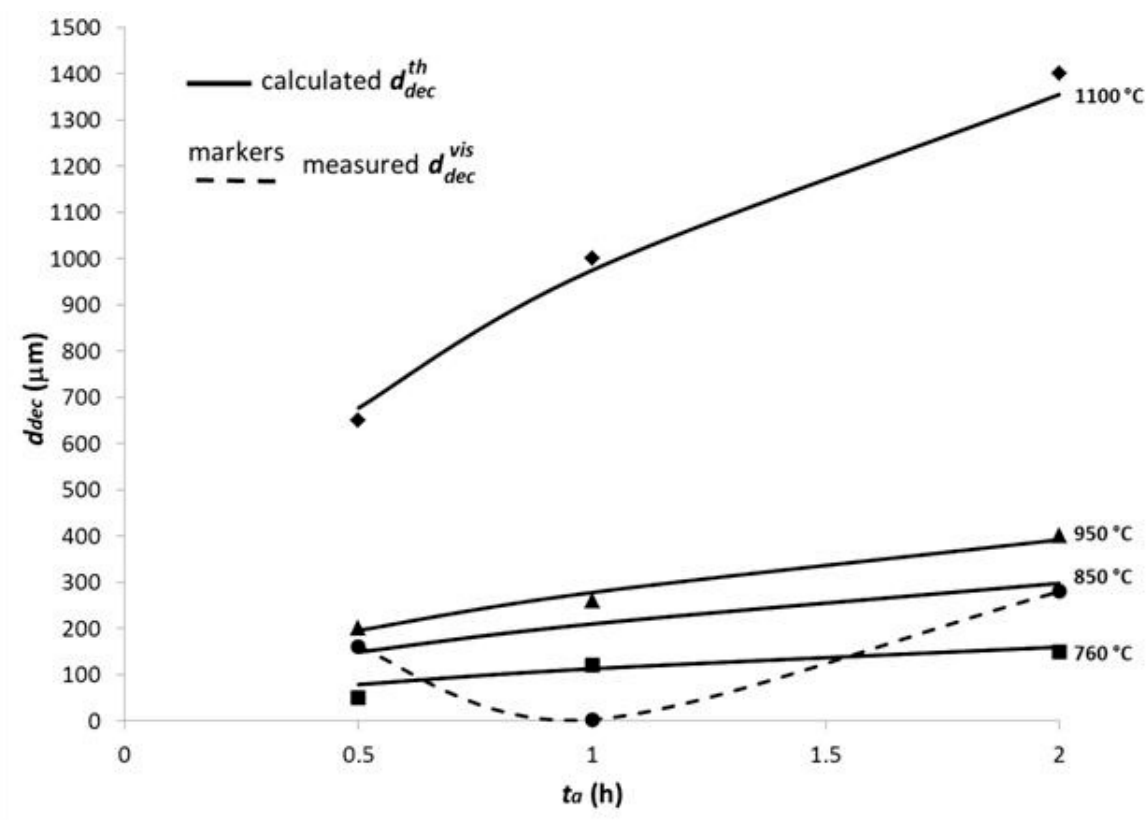

(a)

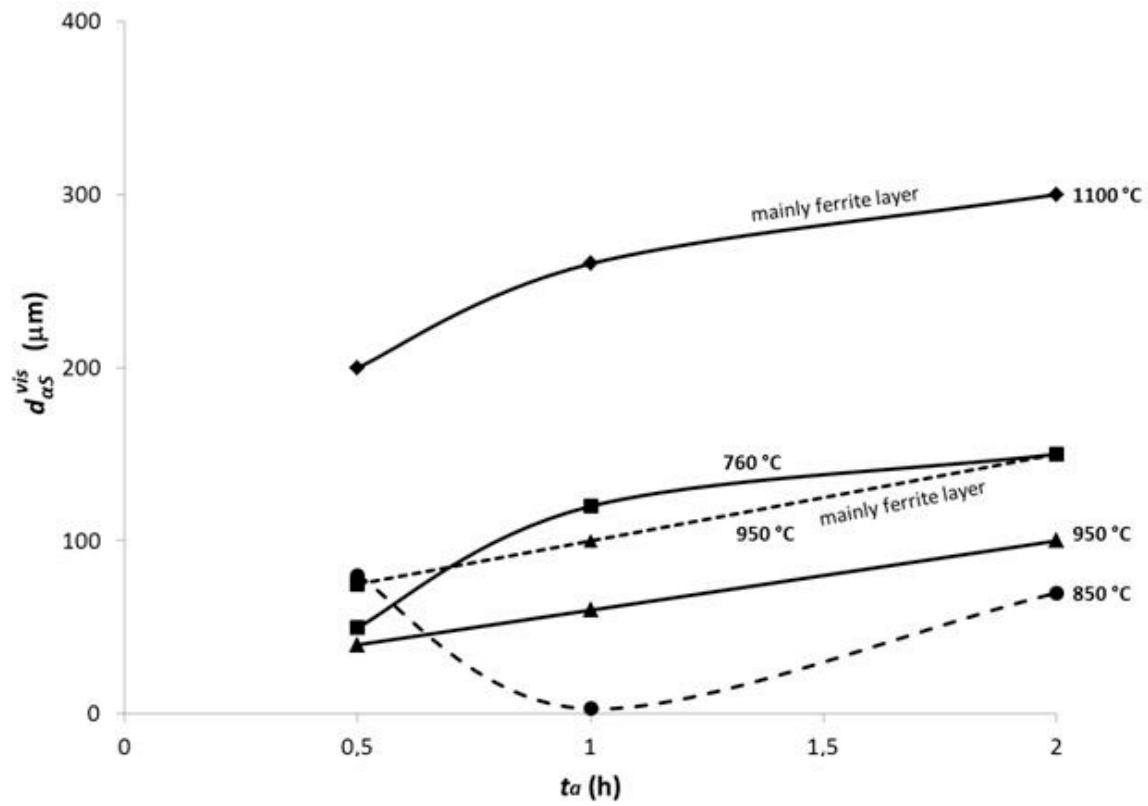

(b)

Figure 10. Cont. 


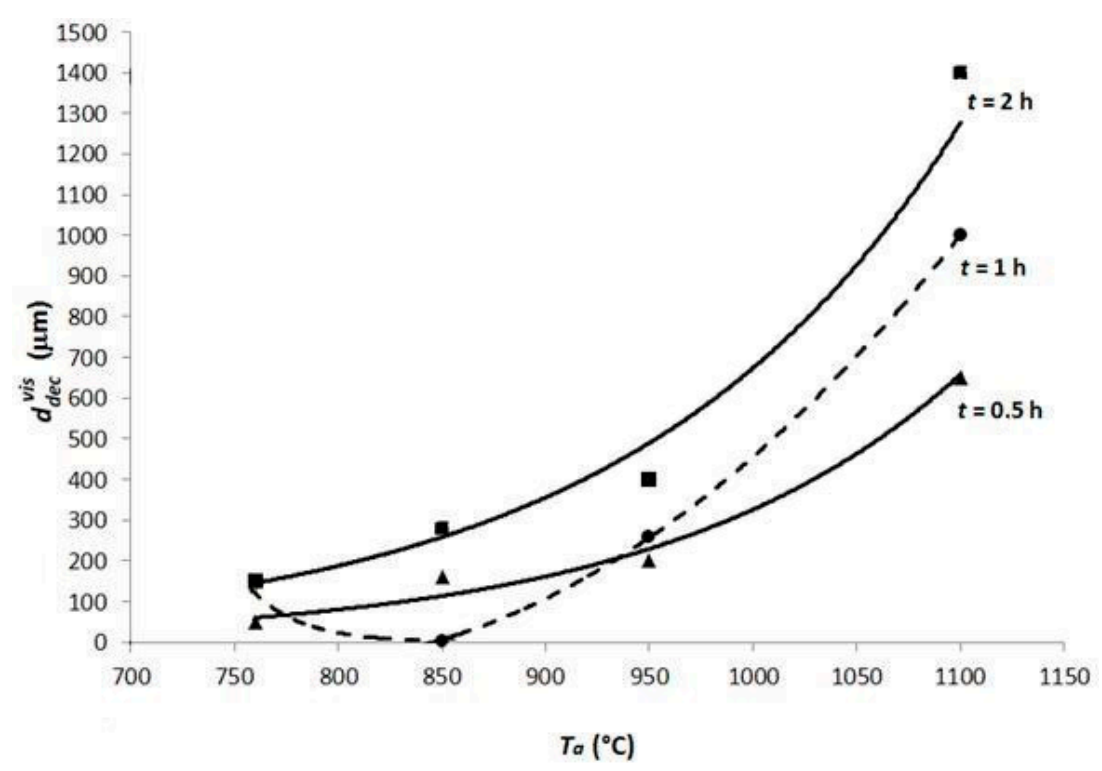

(c)

Figure 10. Visible thickness of decarburization for steel with $C=0.43 \mathrm{wt} \%$. (a) Maximum thicknesses related to annealing time, (b) maximum thicknesses of surface ferrite layer related to annealing time, (c) maximum thicknesses related to temperature.

The time relationship for the maximum thickness of decarburization and the surface ferrite layer is parabolic (Figure 10a,b), while the temperature relation is exponential (Figure 10c). The results show the correspondence between the theoretical and experimental values for the maximum visible decarburization, which is also shown by the $d_{d e c}^{\text {th }} / d_{d e c}^{v i s}$ ratio. The maximum visible depth of decarburization is greater at higher annealing temperatures and longer annealing times; however, this does not apply to the ferrite-only surface layer, as this layer is thinner at $T_{a}=850{ }^{\circ} \mathrm{C}$ and $950{ }^{\circ} \mathrm{C}$ than it is at $760^{\circ} \mathrm{C}$. This is a consequence of the faster oxidation at higher temperatures and of the incubation time required for the sufficient decarburization of the austenite (at $T_{a}=850{ }^{\circ} \mathrm{C}$ austenite must first decarburize to a carbon content $C \gamma_{G-S} \approx 0.13 \mathrm{wt} \%$ and only then will the surface ferrite layer begin to form during the annealing; at $T_{a}=950{ }^{\circ} \mathrm{C}$ austenite must first decarburize to a carbon content $C \gamma_{G-S}<0.02 \mathrm{wt} \%$ for the surface ferrite layer to start forming during cooling). At $T_{a}=850{ }^{\circ} \mathrm{C}$ a time anomaly is revealed with the thickest ferrite layer being present after $\frac{1}{2} \mathrm{~h}$ of annealing. This is definitely a consequence of the process of oxidation overtaking the process of decarburization at longer annealing times and therefore "consuming" more of the decarburized surface layer (the rate of oxidation is equal to or higher than the rate of complete and partial decarburization after $1 \mathrm{~h}$ of annealing, while the speed of decarburization becomes higher than the speed of oxidation after longer annealing times, which is shown by the ferrite layer becoming visible on the surface again). Metallographically measured depths of the visible decarburization are larger than the lowest required $d_{d e c}^{\text {th }} 0.884$ (carbon content $\mathrm{C}=0.38 \mathrm{wt} \%$ ) and are determined in a depth of carbon content $\mathrm{C}=0.39-0.42 \mathrm{wt} \%$. We have therefore metallographically assessed the depth of the visible decarburization with a carbon content of $0.91 C_{0}$ to $0.98 C_{0}$ in a ferrite-pearlite microstructure, which is similar to the findings in $[16,25]$. The results show the amount of surface material necessary to be cut off, so that the hardness of the surface of the C45 steel after quenching will still be acceptable. From Table 2, it is clear that the thickness of the measured ferrite or predominantly ferrite layer is substantially smaller than the $d_{d e c}^{\text {th } 0.884}$ depth (except at $T_{a}=760^{\circ} \mathrm{C}$, which is described later), which confirms the validity of the calculations. If the strength and ductility of the product are more important, then the acceptable depth of decarburization (and therefore also factor $A$ ) can be smaller than $d_{d e c}^{\text {th }} 0.884$ because of the lower strength and not-so-hard low carbon martensite will form in the decarburized surface zone after quenching. Both the ductility 
and the resistance to surface-crack initiation will increase as a consequence, while the strength of the structural component will not be decreased because of the very thin, lower strength surface layer [33].

Theoretically, the obtained values of the visible decarburization might be distinguished from the measured values only at $T_{a}=850{ }^{\circ} \mathrm{C}, t_{a}=1 \mathrm{~h}$. Because there is practically no visible decarburization under these conditions, it means that the $C 45$ steel could possibly be annealed in an air atmosphere at this temperature and for this long a time. In general, a large part of the surface remains visibly non decarburized also under other experimental annealing conditions (except at $T_{a}=760{ }^{\circ} \mathrm{C}, t_{a}=2 \mathrm{~h}$ and $T_{a}=1100{ }^{\circ} \mathrm{C}, \frac{1}{2} \mathrm{~h} \leq t_{a} \leq 2 \mathrm{~h}$, where a continuous completely decarburized surface layer is present). Similar results for a non-alloyed steel with $\mathrm{C}=0.75 \mathrm{wt} \%$, annealed in an air atmosphere at temperatures $T_{a}=800-1000{ }^{\circ} \mathrm{C}$ for $t_{a}=3 \mathrm{~h}$ and $24 \mathrm{~h}$ are given in [4]. Here, it was found that there is no decarburization at the spots where the oxide tightly fits the surface and vice versa. The reasons for such a difference in states of the same surface should therefore be looked for in different fittings of the oxide layer (this is probably somewhat affected by the different rate of oxidation for the individual segments of the surface or of different surfaces; vertical and rounded surfaces oxidize differently than the horizontal ones) and with that connected local cracking of the oxide layer, which is certainly also a consequence of the segregations in steel. The effect of segregations is not shown only in non-decarburized and decarburized segments of the same surface, but also in the decarburized surface layer itself. This is most evident in the samples annealed at $T_{a}=950{ }^{\circ} \mathrm{C}$ for $t_{a}=\frac{1}{2}$ and $2 \mathrm{~h}$ (Figure 8), where segregations are visible as an inserted thin pearlite layer in a completely ferrite surface layer (it is also possible that these kinds of carbon segregations in the surface layer occur during the process of decarburization or even during the cooling of the decarburized austenite).

The visible decarburized layer $d_{d e c}^{v i s}$ is equal to the completely decarburized ferrite layer $d_{\alpha S}^{v i s}$ at the annealing temperature $T_{a}=760{ }^{\circ} \mathrm{C}$ (under the latter there is no partially decarburized layer as the surface ferrite layer borders directly on the non-decarburized steel) because of the decarburization in the two-phase equilibrium state $(\alpha+\gamma)$. The $d_{d e c}^{t h} 0.884$ depth is irrelevant at this temperature because the $d_{d e c}^{t h} 0.884$ values are located in the ferrite layer, as seen in Table 2 . This means that the theoretical model used in practice in this annealing region must always provide a positive deviation from the measured values. If this is not the case, then there will be a remainder of completely decarburized surface ferrite areas left, even after machining the surface, which will consequently cause a soft surface even after quenching. It was found that the absolute depth $x_{0.976}$ with $B \approx 1.6$ is appropriate and it is calculated using Equation (6):

$$
x_{0.976}=2.7798 \cdot \sqrt{t_{a}},(\mu \mathrm{m})
$$

where: $t_{a}$ is the annealing time (s) at the annealing temperature $T_{a}(\mathrm{~K})$. Using an analogy with Equations (11) and (13), the value for $d_{d e c}^{\text {th } 0.976}$ is calculated with the equation:

$$
d_{\text {dec } 0.976}^{\text {th }}=x_{0.976}-d_{m},(\mu \mathrm{m})
$$

The calculated values $x_{0.976}$ and $d_{d e c}^{\text {th }} 0.976$ are given in Table 2 . A larger positive deviation of the calculated values from the measured ones is present only at the annealing time $t_{a}=\frac{1}{2} \mathrm{~h}$. Under these conditions there is a very local surface-decarburized ferrite layer, which is dimensionally almost identical to the bands of non-transformed ferrite in the rest of the volume of the steel. The process of oxidation apparently runs faster than the decarburization or slows it down, which shows the acceptability of annealing in air also for the production of dual-phase steel (ferrite + martensite).

The theoretical model can positively or negatively deviate from the measured values at $T_{a}>A_{\mathrm{C} 3}$ because of the presence of a partially decarburized layer. If the theoretical values show a positive deviation from the measured ones $\left(d_{d e c}^{\text {th }}>d_{d e c}^{\text {vis }}\right)$, then this guarantees that the maximum hardness values based on the Jominy graphs have been achieved. In the case of a negative deviation, the theoretical values must fulfil the condition $d_{d e c}^{t h}>d_{d e c}^{t h} 0.884$ for $C 45$ steel based on the required minimum hardness. If strength and ductility are more important, then $d_{d e c}^{t h}<d_{d e c}^{\text {th } 0.884}$ is also good, but there must be no completely ferrite or predominantly ferrite surface layer present after machining of the surface; 
therefore, the $d_{d e c}^{\text {th }}>d_{\alpha S}^{v i s}$ condition must always be met. A surface layer of ferrite is therefore always forbidden.

\section{Conclusions}

The hypo-eutectoid carbon steel C45 with a carbon content $\mathrm{C}=0.43 \mathrm{wt} \%$ and with an initial ferrite-pearlite microstructure, having a grinded, non-oxidised surface, was isothermally annealed in steady air at temperatures $T>A_{\mathrm{C} 1}$ in three temperature regions $\left(A_{\mathrm{C} 1}<T_{a}<A_{\mathrm{C} 3}, A_{\mathrm{C} 3}<T_{a}<T_{G}\right.$ in $T_{a}>T_{G}$ ) and times $t_{a}=\frac{1}{2}, 1,2 \mathrm{~h}$. On the basis of the experimental and theoretical results, we can conclude the following for pieces with a mass $m \leq 180 \mathrm{~g}$ :

- The oxidation, the maximum visible decarburization of the surface and the completely decarburized ferrite layer grow with longer annealing times in accordance with the parabolic law of growth. The thickness of the decarburized layer increases exponentially with higher temperatures. The reasons for some global and local discrepancies in practice (total absence of decarburization, thinner completely decarburized ferrite surface layer at higher temperatures, locally limited decarburization) must be searched for in the ratio of the rates of oxidation and decarburization, the different fittinsg of the oxide layer on the steel surface, the local peeling off and cracking of the oxide layer and with that the associated different rates of oxidation for the individual local segments, the effect of segregations on the kinetics of oxidation and decarburization, the effect of segregations on the local peeling off, and the cracking of the oxide layer.

- Under the annealing conditions $T_{a}=850{ }^{\circ} \mathrm{C}, t_{a}=1 \mathrm{~h}$ there is no visible decarburization. This means that under these conditions, the oxidation of the surface of $\mathrm{C} 45$ steel that was grinded prior to annealing is faster than the decarburization and that normalization and annealing for quenching can be performed in an air atmosphere. Because of the very locally limited minimal decarburization at $T_{a}=760^{\circ} \mathrm{C}, t_{a}=\frac{1}{2} \mathrm{~h}$ it is acceptable to also perform annealing for a dual-phase (ferrite + martensite) microstructure in an air atmosphere under these conditions. Under all other annealing conditions, it is necessary to introduce measures for the prevention of decarburization or to take into account the addition of thickness prior to the annealing, which is the sum of the thicknesses of both the oxidized layer and the visible decarburized layer.

- A completely ferrite surface layer without a partially decarburized layer exists only in the samples that were annealed at $T_{a}=760{ }^{\circ} \mathrm{C}\left(A_{\mathrm{C} 1}<T_{a}<A_{\mathrm{C} 3}\right)$ in a dual-phase region $(\alpha+\gamma)$. This is a consequence of the specific course of the austenite decarburization at the inner boundary of the ferrite layer in conditions of constant and time-independent thermodynamic equilibrium between the ferrite and austenite grains in the whole volume of an annealed piece. These conditions do not allow the partial decarburization towards the interior to occur, as is the case with pieces annealed at $T_{a}>A_{\mathrm{C} 3}$.

- A continuous, visible, decarburized ferrite layer forms only under the annealing conditions $T_{a}=760{ }^{\circ} \mathrm{C}, t_{a}>1 \mathrm{~h}$, while at $T_{a}=1100^{\circ} \mathrm{C}, \frac{1}{2} \mathrm{~h} \leq t_{a} \leq 2 \mathrm{~h}$ (steel is very overheated here) there is a partially decarburized layer spread towards the interior under the continuous surface ferrite layer. Under all other annealing conditions there are only local decarburized surface layers in which there is, besides a partial decarburization, also a thin superficial, completely ferrite layer observed. This layer forms already during the annealing at the annealing temperatures $A_{\mathrm{C} 1}<T_{a}<T_{G}$, while at $T_{a}>T_{G}$ it only forms later, during the cooling of the completely decarburized austenite. The thickest strongly decarburized surface layer is formed at $T_{a}=1100{ }^{\circ} \mathrm{C}$, which is a consequence of the high temperatures and their effect on the oxidation and decarburization of the steel surface.

- Even though the Van-Ostrand-Dewey equation was developed for the decarburization of austenite $\left(T_{a}>T_{G}\right)$, the results show that it can be used, at least in certain time periods, for all annealing temperatures $T_{a}>A_{\mathrm{C} 1}$, which widens the temperature region of its use considerably. 
- With the method of trial and error, the Van-Ostrand-Dewey equation enables the adjustment of calculated values with experimental measurements and an assessment of the accuracy of the measurements for different experimental techniques. The metallographically and theoretically measured depths of decarburization with a carbon content of $0.91 C_{0}$ to $0.98 C_{0}$ in a ferrite-pearlite microstructure, formed during cooling in steady air, can be adjusted, in general, with a $93 \%$ to $98 \%$ accuracy.

- The most suitable equation for calculating the diffusion coefficient of carbon in austenite for the researched experimental state is also determined by the Van-Ostrand-Dewey equation. Because of the completely decarburized austenite in the surface layer, the equation that gives the lowest values for the diffusion coefficient of carbon in austenite at annealing temperatures $T_{a}(\mathrm{~K})$ is appropriate: $D_{\mathrm{C} \gamma}=0.23 \cdot e^{-148000 /\left(R \cdot T_{a}\right)}\left(\mathrm{cm}^{2} / \mathrm{s}\right) ; R=8.314 \mathrm{~J} / \mathrm{mol} \cdot \mathrm{K}$.

- The equations used to calculate the thickness of oxidized steel $d_{m}$ and the absolute depth of the decarburization $x_{A}$ can also be used to precisely theoretically determine the visible decarburization $d_{d e c}^{\text {th }}$ of the C45 steel with a difference of both quantities $d_{d e c}^{\text {th }}=x_{A}-d_{m}$. This shows that the equation for growth of the oxide layer $d_{0 x}$ on iron, from which the thickness of the oxidized iron $d_{m}$ is calculated, also describes the oxidation of non-alloyed steel in steady air relatively well, even though the literature stated a slower oxidation of non-alloyed steel in comparison with iron.

- Most types of annealing take place at temperatures $T>A_{\mathrm{C} 3}$; therefore, the addition of thickness, which has to be more than the absolute depth of the decarburization $x_{0.884}$, must be taken into account before annealing in steady air for C 45 steel with $\mathrm{C}=0.43 \mathrm{wt} \%$ to achieve the required hardness. In the case of the annealing conditions at which visible decarburization does not exist, the additional thickness only has to be greater than the calculated thickness of the oxidized steel $d_{m}$. When annealing for the production of dual-phase steel under the annealing conditions $T_{a}=760{ }^{\circ} \mathrm{C}, t_{a} \geq 1 \mathrm{~h}$, it is necessary to ensure the addition of thickness in the size of the absolute depth of decarburization $x_{A}=x_{0.976}$, because of the removal of the surface ferrite layer.

Author Contributions: M.Z. carried out the literature review, performed the experiments, made the measurements, analysed the data and constructed the diagrams. B.Z. defined the research program, carried out the metallography, analysed the results and wrote the paper. A.N. optimized the research program, improved the idea for the paper, analysed the data and revised the paper. J.B. analysed the data and revised the paper. The annealing furnace is owned by B.K. was responsible for controlling and measuring the temperature.

Conflicts of Interest: The authors declare no conflict of interest.

\section{References}

1. Leslie, W.C. The Physical Metallurgy of Steels; McGraw-Hill Inc.: London, UK, 1982; pp. 74-81, ISBN 0-07-066385-8.

2. De Cooman, B.C.; Speer, J.G. Fundamentals of Steel Product Physical Metallurgy; AIST: Warrendale, PA, USA, 2011; pp. 61-64, 37-42.

3. Billings, G.A. Oxidation and Decarburization Kinetics of Iron-Carbon Alloys in Carbon Dioxide-Carbon Monoxide Atmosphere. Master's Thesis, McMaster University, Hamilton, ON, Canada, 1966.

4. Marston, H.F.; Rose, A.J.; Abbot, R.E.; Bugdol, M.; Richardson, W. Oxidation and Decarburization of High Carbon Steels; Final Report; European Commission, Directorate-General Science, Research and Development: Luxembourg, 1998; pp. 14, 15, 52, 53, 65, 66, ISBN 92-828-4548-6.

5. Mardon, C. The Austenitization and Decarburization of High Silicon Spring Steel. Ph.D. Thesis, University of Canterbury, Christchurch, New Zealand, 1998.

6. Mayott, S.W. Analysis of the Effect of Reduced Oxygen Atmospheres on the Decarburization Depth of 300M Alloy Steel. Master's Thesis, Rensselaer Polytechnic Institute, Department of Materials Science and Engineering, New York, NY, USA, 2010.

7. Zhang, C.L.; Zhou, L.Y.; Liu, Y.Z. Surface decarburization characteristics and relation decarburized types and heating temperature of spring steel 60Si2MnA. Int. J. Miner. Metall. Mater. 2013, 20, 720-724. [CrossRef] 
8. Liu, Y.; Zhang, W.; Tong, Q.; Wang, L. Effects of Temperature and Oxygen Concentration on the Characteristics of Decarburization of 55SiCr Spring Steel. ISIJ Int. 2014, 54, 1920-1926. [CrossRef]

9. Zhao, F.; Zhang, C.L.; Liu, Y.Z. Ferrite decarburization of high silicon spring steel in three temperature ranges. Arch. Metall. Mater. 2016, 61, 1715-1722. [CrossRef]

10. Schumann, H. Metallographie; 12. Auflage; VEB-DVG: Leipzig, Germany, 1983; pp. 316-321, 368, 150-152, ISBN 3-342-00009-0.

11. Zorc, M. Decarburization of Non-Alloy Medium Carbon Steel during Annealing in an Air Atmosphere. Bachelor's Thesis, University of Ljubljana, Faculty of Natural Sciences and Engineering-Department of Materials and Metallurgy, Ljubljana, Slovenia, 2016.

12. Hasegava, M. Ellingham Diagram. In Treatise on Process Metallurgy-Vol. 1: Process Fundamentals; Seetharaman, S., Ed.; Elsevier: Oxford, UK, 2013; pp. 507-516, ISBN 9870080969862.

13. Vodopivec, F. Kovine in Zlitine (Metals and Alloys, in Slovenian); Inštitut za Kovinske Materiale in Tehnologijo: Ljubljana, Slovenia, 2002; pp. 159-164, ISBN 961-238-084-8.

14. Chen, R.Y.; Yuen, W.Y.D. Review of the High-Temperature Oxidation of Iron and Carbon Steels in Air or Oxigen. Oxid. Met. 2003, 59, 433-468. [CrossRef]

15. Kveder, A. (Ed.) Metalurški Priročnik (Handbook of Metallurgy, in Slovenian); Tehniška Založba Slovenije: Ljubljana, Slovenia, 1972; pp. 232, 233, 759.

16. Liščić, B. Steel Heat Treatment. In Steel Heat Treatment Handbook, 2nd ed.; Totten, G.E., Ed.; CRC Press-Taylor \& Francis Group: Boca Raton, FL, USA, 2007; pp. 277-414, ISBN 987-0-8493-8455-4.

17. Gontarev, V. Teorija Metalurških Procesov (Theory of Metallurgical Processes, in Slovenian); Univerza v Ljubljani, NTF-Oddelek Za Materiale in Metalurgijo: Ljubljana, Slovenia, 2005; pp. 27-32, ISBN 961-6047-30-2.

18. Naumann, F.K. Das Buch der Schadensfälle; Dr. Riederer-Verlag GmbH: Stuttgart, Germany, 1976; p. 181.

19. Rose, A.; Peter, W.; Strassburg, W.; Rademacher, L. Atlas zur Wärmebehandlung der Stähle-Teil II; Verlag Stahleisen M.B.H.: Düsseldorf, Germany, 1961; p. II-101A.

20. Vander Voort, G.F. Understanding and Measuring Decarburization. Adv. Mat. Process. 2015, 173, $22-27$.

21. Gegner, J. Diffusion Modelling of Decarburization Microhardness-Distance Profiles. Available online: https: / / www.ariel.ac.il/sites/conf/mmt/MMT-2006/Service_files/papers/Session_1/1-168_di.pdf (accessed on 28 April 2017).

22. Choi, S.; van der Zwaag, S. Prediction of Decarburized Ferrite Depth of Hypoeutectoid Steel with Simultaneous Oxidation. ISIJ Int. 2012, 52, 549-558. [CrossRef]

23. Cioffi, R.D. A Comparison Study on Depth of Decarburization and the Role of Stable Carbide Forming Elements in 1075 Plain Carbon Steel and 440A Stainless Steel; Rensselaer Polytechnic Institute, Department of Materials Science and Engineering: New York, NY, USA, 2012.

24. Choi, S.; Lee, Y. An Approach to predict the Depth of the Decarburized Ferrite Layer of Spring Steel Based on Measured Temperature History of material during Cooling. ISIJ Int. 2014, 54, 1682-1689. [CrossRef]

25. Birks, N. Mechanism of decarburization. In Decarburization; ISI Publication 133; The Iron and Steel Institute: London, UK, 1970; pp. 1-12, ISBN 0900497165.

26. Wells, C.; Batz, W.; Mehl, R.F. Diffusion Coefficient of Carbon in Austenite. J. Met. 1950, 188, 553-560. [CrossRef]

27. Bhadeshia, H.K.D.H.; Honeycombe, R.W.K. Steels Microstructure and Properties, 3rd ed.; Elsevier: Oxford, UK, 2006; pp. 11-12, ISBN 978-0-750-68084-4.

28. Callister, W.D., Jr. Material Science and Engineering-An Introduction, 7th ed.; John Wiley \& Sons, Inc.: New York, NY, USA, 2007; p. 119, ISBN 978-0-471-73696-7.

29. Porter, D.A.; Easterling, K.E. Phase Transformations in Metals and Alloys, 2nd ed.; Chapman \& Hall: London, UK, 1992; pp. 7, 74, ISBN 0-412-450030-5.

30. Error Function Table. ECE 3610 Engineering Probability \& Statistics. Available online: https:/ / www.geophysik.uni-muenchen.de/Members/mohr/materials/ComputationalGeophysics2017/ ?searchterm=Function\%20Table (accessed on 16 May 2017).

31. Ericsson, T. Principles of Heat Treating of Steels. In ASM Handbook-Vol. 4: Heat Treating; Lampman, S.R., Zorc, T.B., Eds.; ASM International@: Materials Park, OH, USA, 2009; pp. 3-19, ISBN 978-0-87170-379-8. 
32. CEN Brussels, B. Standard EN 10083-2/2006: Steels for Quenching and Tempering_Part 2: Technical Delivery Conditions for Non Alloy Steels. ICS 77.140.10, 2006.

33. Jaason, K.; Peetsalu, P.; Saarna, M.; Kulu, P.; Beilmann, J. Decarburisation Effect on Hardened Strip Steel Fastening Components. Mat. Sci. 2016, 22, 148-152. [CrossRef] 